\title{
Review \\ Structural Determinants and Their Role in Cyanobacterial Morphogenesis
}

\author{
Benjamin L. Springstein ${ }^{1, *(\mathbb{C})}$, Dennis J. Nürnberg ${ }^{2} \mathbb{C}$, Gregor L. Weiss ${ }^{3}\left(\mathbb{C}\right.$, Martin Pilhofer $^{3}(\mathbb{D}$ \\ and Karina Stucken ${ }^{4}$ (D) \\ 1 Department of Microbiology, Blavatnik Institute, Harvard Medical School, Boston, MA 02115, USA \\ 2 Department of Physics, Biophysics and Biochemistry of Photosynthetic Organisms, Freie Universität Berlin, \\ 14195 Berlin, Germany; dennis.nuernberg@fu-berlin.de \\ 3 Department of Biology, Institute of Molecular Biology \& Biophysics, ETH Zürich, 8092 Zürich, Switzerland; \\ gregor.weiss@mol.biol.ethz.ch (G.L.W.); pilhofer@mol.biol.ethz.ch (M.P.) \\ 4 Department of Food Engineering, Universidad de La Serena, La Serena 1720010, Chile; kstucken@userena.cl \\ * Correspondence: benjamin_springstein@hms.harvard.edu
}

Received: 2 November 2020; Accepted: 9 December 2020; Published: 17 December 2020

check for updates

\begin{abstract}
Cells have to erect and sustain an organized and dynamically adaptable structure for an efficient mode of operation that allows drastic morphological changes during cell growth and cell division. These manifold tasks are complied by the so-called cytoskeleton and its associated proteins. In bacteria, FtsZ and MreB, the bacterial homologs to tubulin and actin, respectively, as well as coiled-coil-rich proteins of intermediate filament (IF)-like function to fulfil these tasks. Despite generally being characterized as Gram-negative, cyanobacteria have a remarkably thick peptidoglycan layer and possess Gram-positive-specific cell division proteins such as SepF and DivIVA-like proteins, besides Gram-negative and cyanobacterial-specific cell division proteins like MinE, SepI, ZipN (Ftn2) and ZipS (Ftn6). The diversity of cellular morphologies and cell growth strategies in cyanobacteria could therefore be the result of additional unidentified structural determinants such as cytoskeletal proteins. In this article, we review the current advances in the understanding of the cyanobacterial cell shape, cell division and cell growth.
\end{abstract}

Keywords: cyanobacteria; morphology; cell division; cell shape; cytoskeleton; FtsZ; MreB; IF proteins

\section{Introduction}

One of the major perquisites of cellular functions is a structured and coordinated internal organization. Cells have to build and sustain or, if appropriate, modify their shape, which allows them to rapidly change their behavior in response to external factors. During different life cycle stages, such as cell growth, cell division or cell differentiation, internal structures must dynamically adapt to the current requirements. In eukaryotes, these manifold tasks are fulfilled by the cytoskeleton: proteinaceous polymers that assemble into stable or dynamic filaments or tubules in vivo and in vitro. The eukaryotic cytoskeleton is historically divided into three classes: the actin filaments (consisting of actin monomers), the microtubules (consisting of tubulin subunits) and the intermediate filaments (IFs), although other cytoskeletal classes have been identified in recent years [1,2]. Only the collaborative work of all three cytoskeletal systems enables proper cell mechanics [3]. The long-lasting dogma that prokaryotes, based on their simple cell shapes, do not require cytoskeletal elements was finally abolished by the discovery of FtsZ, a prokaryotic tubulin homolog [4-6] and MreB, a bacterial actin homolog $[7,8]$. These discoveries started an intense search for other cytoskeletal proteins in bacteria and archaea which finally led to the identification of bacterial IF-like proteins such as Crescentin from Caulobacter crescentus [9] and even bacterial-specific cytoskeletal protein classes, 
including bactofilins [10]. Constant influx of new findings finally established that numerous prokaryotic cellular functions, including cell division, cell elongation or bacterial microcompartment segregation are governed by the prokaryotic cytoskeleton (reviewed by [11,12]).

Cyanobacteria are today's only known prokaryotes capable of performing oxygenic photosynthesis. Based on the presence of an outer membrane, cyanobacteria are generally considered Gram-negative bacteria. However, unlike other Gram-negative bacteria, cyanobacteria contain an unusually thick peptidoglycan (PG) layer between the inner and outer membrane, thus containing features of both Gram phenotypes [13-15]. Additionally, the degree of PG crosslinking is much higher in cyanobacteria than in other Gram-negative bacteria, although teichoic acids, typically present in Gram-positive bacteria, are absent [16]. The processes of PG biosynthesis and the proteinaceous components involved in the composition of the cyanobacterial PG were previously reviewed [17] and will not be part of this review.

While Cyanobacteria are monophyletic [18], their cellular morphologies are extremely diverse and range from unicellular species to complex cell-differentiating, multicellular species. Based on this observation, cyanobacteria have been classically divided into five subsections [19]. Subsection I cyanobacteria (Chroococcales) are unicellular and divide by binary fission or budding, whereas subsection II cyanobacteria (Pleurocapsales) are also unicellular but can undergo multiple fission events, giving rise to many small daughter cells termed baeocytes. Subsection III comprises multicellular, non-cell differentiating cyanobacteria (Oscillatoriales) and subsection IV and V cyanobacteria (Nostocales and Stigonematales) are multicellular, cell differentiating cyanobacteria that form specialized cell types in the absence of combined nitrogen (heterocysts), during unfavorable conditions (akinetes) or to spread and initiate symbiosis (hormogonia). Whereas subsections III and IV form linear cell filaments (termed trichomes) that are surrounded by a common sheath, subsection $\mathrm{V}$ can produce lateral branches and/or divide in multiple planes, establishing multiseriate trichomes [19]. Considering this complex morphology, it was postulated that certain subsection V-specific (cytoskeletal) proteins could be responsible for this phenotype. However, no specific gene was identified whose distribution was specifically correlated with the cell morphology among different cyanobacterial subsections [20,21]. Therefore, it seems more likely that differential expression of cell growth and division genes rather than the presence or absence of a single gene is responsible for the cyanobacterial morphological diversity [20,22]. In the heterocystous cyanobacterium Anabaena sp. PCC 7120 (hereafter Anabaena), the multicellular shape is strictly dependent on cell-cell communication through gated proteinaceous complexes, termed septal junctions, which resemble eukaryotic gap junctions [23] and allow the diffusion of small regulators and metabolites such as sucrose [24]. Septal junctions pierce through the nanopores in the septal PG mesh, which are drilled by AmiC amidases [25]. Additionally, isolated PG sacculi suggest that the PG mesh from neighboring cells is connected, allowing the isolation of seemingly multicellular PG sacculi $[25,26]$. Several components are putatively involved in the function, formation and integrity of septal junctions, including septal-localized proteins such as SepJ (formerly also known as FraG [27]), SepI, FraC and FraD as well as AmiC1/2/3 and the PG-binding protein SjcF1, but only FraD was unambiguously shown to be a direct component of the septal junctions [23]. For reviews on cell-cell communication and the general multicellular nature of Anabaena see [28-30]. Here we will review the structural and environmental determinants of cyanobacterial shape, division and growth, focusing on the role of cytoskeletal proteins.

\section{How Do Cyanobacteria Modify Their Cell Shape?}

\subsection{Morphology and Environmental Cues}

Cyanobacteria show a high degree of morphological diversity and can undergo a variety of cellular differentiation processes in order to adapt to certain environmental conditions. This helps them thrive in almost every habitat on Earth, ranging from freshwater to marine and terrestrial habitats, 
including even symbiotic interactions [31]. One factor which can drive morphological changes in cyanobacteria is light.

As cyanobacteria are bacteria that use light to fuel their energy-producing photosynthetic machinery they depend on perceiving light in order to optimize their response and to avoid harmful light that could result in the formation of reactive oxygen species (ROS) and subsequently in their death (reviewed by [32]). Optimal light conditions may be defined by quantity (irradiance), duration (day-night cycle) and wavelength (i.e., the color of light). The photosynthetically useable light range of the solar spectrum is generally referred to as PAR (photosynthetically active radiation), but some cyanobacteria may expand on PAR by not only absorbing in the visible spectrum, but also the near-infrared light spectrum. This employs a variety of chlorophylls and allows phototrophic growth up to a wavelength of $750 \mathrm{~nm}$ (reviewed by [33]). To sense the light across this range of wavelengths, cyanobacteria possess various photoreceptors of the phytochrome superfamily (reviewed by [34]).

Some filamentous cyanobacteria such as Fremyella diplosiphon (also called Calothrix sp. PCC 7601 or Tolypothrix sp. PCC 7610) are predicted to encode up to 27 unique phytochrome superfamily photoreceptors, mostly of unknown function [35]. F. diplosiphon has been, however, well studied regarding a process called complementary chromatic acclimation (CCA) [36,37]. When the organism is grown under green light, it changes the composition of its light harvesting antennas, the phycobilisomes, by synthesizing phycoerythrin. Under red light, the pigment phycocyanin is introduced instead. This allows the organism to fine-tune its photosynthetic machinery and to generate sufficient energy for growth under changing light conditions. The photoreceptor that is linked with the pigment change was identified as the sensor kinase RcaE [38,39]. rcaE deletion mutants of F. diplosiphon furthermore revealed the importance of RcaE for cell morphology and shape [40]. When grown under red light, cells show generally a more coccoid cell shape and trichomes are short, whereas under green light the filaments are long, and cells become rod-shaped [36]. This change is regulated by RcaE [40] through its regulatory effect on the expression of the transcriptional regulator BolA. Under red light, the auto-kinase activity of RcaE activity promotes the upregulation of bolA expression. BolA in turn binds to the promoter region of $m r e B$, inhibiting transcription while under green light, lower levels of BolA result in an accumulation of MreB leading to rod-shaped cells [41]. $r c a E$ deletion mutants were unable to change their morphology and remained coccoid under the different light conditions [40].

Phytochromes are also involved in phototaxis and motility, as it has been shown in Synechocystis sp. PCC 6803 (hereafter Synechocystis) (reviewed by [42]). In some filamentous cyanobacteria of the order Nostocales phototaxis is facilitated by the formation of motile hormogonia in response to the colour of light and its irradiance [43-46]. In F. diploshiphon for example, the formation of hormogonia is induced by red light while green light suppresses their induction [45,47]. However, hormogonia formation differs from other cyanobacterial differentiation processes such as heterocyst formation by the fact that it can be initiated by various other environmental cues, including nutrient concentrations and signals from symbiotic partners [48-51]. Once hormogonia formation has been initiated, a cascade of cellular development follows. This includes the synchronous division of cells, the fragmentation of trichomes at heterocyst-vegetative cell junctions and necridia (apoptotic cells), a reduction in cell volume and sometimes the formation of tapered filament termini [44]. We have shown in hormogonia from the branching cyanobacterium Mastigocladus laminosus SAG 4.84 that molecular exchange between neighboring cells is fast and that the reduction in cell volume could even further accelerate signal transduction to coordinate movement [52]. During gliding motility cell growth and division are arrested [53] but once the hormogonium reaches its destination, e.g., the host, cells elongate, divide and potentially differentiate into heterocysts. Various hosts have been identified for cyanobacteria, including bryophytes (hornworts, liverworts), the angiosperm Gunnera, the aquatic fern Azolla, fungi (forming lichens), the fungus Geosiphon, cycads and diatoms [54,55]. The cyanobiont (cyanobacterial symbiont) can either grow intracellularly or extracellularly in specialized compartments. For example in the case of the Anabaena-Azolla symbiosis the cyanobacterium resides in the leaf pockets of the fern [56]. Internal symbionts have additional challenges. Once inside the host, cell division needs 
to be regulated to avoid bursting of the cells. Indeed, it has been observed that the cyanobacterium Calothrix rhizosoleniae grows in shorter trichomes when inside the host cell than in its free-living state [57]. The signals and mechanisms behind the restricted growth remain basically unknown.

Although not further discussed in this review, cellular morphology can be changed by nutrient composition [58] as well as stresses such as temperature, salt, ultraviolet (UV) light and drought and are connected with the formation of ROS (reviewed by [59]). The aforementioned examples show the complexity and diversity of the environmental cues that influence morphology and cell shape in cyanobacteria. In the following paragraphs we will address the underlying genetic and structural components that are associated with the different morphologies.

\subsection{Morphological Plasticity in Cyanobacteria}

Morphological plasticity, or the ability of one cell to alternate between different shapes, is a common strategy of many bacteria in response to environmental changes or as part of their normal life cycle (reviewed by [60-62]). Bacteria may alter their shape by simpler transitions from rod to coccoid (and vice versa) as in Escherichia coli [63], by more complex transitions while establishing multicellularity (reviewed by [60]) or by the development of specialized cells, structures or appendages where the population presents a pleomorphic lifestyle [64]. The precise molecular circuits that govern those morphological changes are yet to be identified, however, a so-far constant factor is that the cell shape is determined by the rigid PG sacculus which consists of glycan strands crosslinked by peptides. To grow, cells must synthesize new PG while breaking down the existent polymer to insert the newly synthesized material. How cells grow and elongate has been extensively reviewed in model organisms of both, rod-shaped [65,66] and coccoid bacteria [67]. The molecular basis for morphological plasticity and pleomorphism in more complex bacteria, however, is slowly being elucidated as well (see a recent review by [62]). The protein complex responsible for cell wall elongation in rod-shaped bacteria is referred to as the elongasome and is composed of, among others, MreB, MreC, MreD, PBP2, PBP1A, RodA and RodZ $[65,68,69]$. MreB polymerizes into dynamic filaments that act as a scaffold ion which the PG synthesis machinery assembles [70,71]. MreB orchestrates elongasome assembly through interaction with transmembrane proteins, such as RodZ and MreC/D [65] and the direct involvement of MreB in cell wall morphogenesis was described upon the correlation between MreB polymers and PG deposition along the lateral cell wall [72-74].

The phylogenetic distribution of MreB seems to be ubiquitous in rod-shaped bacteria, which encode for at least one $m r e B$ homolog whereas, with few exceptions, coccoid bacteria lack $m r e B$, supporting the theory that coccoid bacteria evolved from rods [75]. In fact, out of 253 sequenced bacterial genomes representing all possible shapes, $63 \%$ of the transitions from rod to coccoid were related to the loss of $m r e B$ [76]. In accordance with this hypothesis, an analysis of 141 fully sequenced cyanobacterial genomes found that only four species lack mreB. The four species included Synechocystis, Crocosphaera watsonii WH 8501, Atelocyanobacterium thalassa ALOHA and Gloeocapsa sp. PCC 73106, all of which are unicellular and coccoid. In all these cyanobacteria, the loss of $m r e B$ was accompanied by the loss of the complete mreBCD operon [77]. Among the myriad cyanobacterial shapes, all multicellular or baeocyte-forming cyanobacteria, independent of their cell shape, had a complete mreBCD operon, suggesting that the coccoid shape in some of those multicellular cyanobacteria is achieved by alternative mechanisms than simply a lack of MreB [77]. Few other cyanobacterial taxa have retained only a copy of mreB on their genomes and lack mreC and mreD. For example, the multicellular cyanobacterium Trichodesmium erythraeum contains only a partial mreBCD operon that lacks $m r e D$, while the filamentous helical shaped Arthrospira maxima CS-328 only encodes for mreB [77]. Likewise, the helical shaped Helicobacter pylori contains both MreB and MreC but lacks MreD. However, mreB is not essential in this bacterium and is not involved in cell shape-determination [78]. Instead, a family of endopeptidases actively remodels and flexibilizes the PG crosslinks that enable the helical cell curvature needed for the successful colonization of the human stomach [79]. Likewise, the transition from helical to straight trichomes [80], could be governed by other proteins than MreB instead. 
There are few studies that have tried to elucidate the role of MreB in cyanobacteria and even less that succeeded in obtaining mreB deletion mutants either partially or completely segregated. However, the common denominator of these studies is a function of MreB in cell shape maintenance, independent of the cyanobacterial morphology [81-84]. In the rod-shaped Synechococcus elongatus PCC 7942 (hereafter Synechococcus) and Synechococcus sp. PCC 7002, MreB appears to be essential [81,82] as only partially segregated mutants could be obtained. In both Synechococcus species partial loss of $m r e B$ resulted in cell shape defects where cells became more coccoid (Figure 1). As a result of the polyploid nature of cyanobacteria and their asynchronous DNA replication (reviewed by [85]), most cyanobacterial studies on MreB have focused on elucidating the role of this protein in chromosome partitioning. Indeed, mreB knockdown mutants in Synechococcus show disarranged chromosomal replication origin (ori)-foci, suggesting that MreB is involved in chromosomal positioning [83]. However, the role of MreB in chromosomal positioning seems to be species-specific as chromosome partitioning was not affected in a mreB Synechococcus sp. PCC 7002 depletion mutant [82]. Furthermore, MreB seems to be involved in cellular compartmentalization in Synechococcus as mreB mutants show altered carboxysome placements. However, this effect is likely indirect in which the function of MreB in cell shape determination provides the necessary structural framework to organize carboxysomes [81]. A similar pleiotropic and indirect effect might also explain the alterations in chromosome positioning in the Synechococcus mreB knockdown mutant [83]. A notable exception of the essential nature of $m r e B$ is Anabaena where $m r e B$ affects cell shape but was found to be dispensable for cell viability with combined nitrogen and did not affect chromosome segregation or placement [84]. Anabaena mreB, mreC and mreD deletion mutants were all characterized by an alteration of cell size, regardless of the growth conditions [58]. In wild type Anabaena, single cells are longer than they are wide (in respect to the trichome growth axis). In the $m r e B, m r e C$ and $m r e D$ mutants, however, cells became more coccoid and seemingly inverted their orientation within the trichome, being wider than long (Figure 1). MreB, MreC and MreD additionally affected the Anabaena trichome length, possibly through a strengthening of the septal cell wall, which was found to be increased in diameter in the three mutants [58].

Cells within the trichomes of the multiseriate and branching cyanobacteria Fischerella muscicola PCC 7414 may display rod, coccoid or tapered shapes while also differing in cell size $[19,93]$. F. muscicola also shows alternative growth modes that include apical, septal, and lateral trichome growth, although it is still not known how MreB contributes to cell shape or PG synthesis in this cyanobacterium. Deletions of mreB could not be obtained in F. muscicola, but overexpression of GFP-MreB from the copper inducible petE promoter showed alternative MreB localization in the different cell morphotypes (hormogonia, young and mature trichomes) from F. muscicola [77]. Further assessment of mreB regulation and localization dynamics in the different morphotypes is necessary to elucidate the role of this protein in the morphogenesis of complex multicellular and branching cyanobacteria.

The above-described observations attribute a largely structural function to MreB in cyanobacteria, however, MreB has also been indicated to be involved in other cellular processes. Spiroplasma eriocheiris, a cell wall-less helical bacterium with swimming motility encodes for five MreB variants [94]. Together with the fibril protein, MreB was proposed to contribute to the propelling mechanism of S. eriocheiris by coordinating the length changes of their cytoskeletal ribbons [95]. Unlike any other cyanobacterium, some marine Synechococcus move by swimming using a still unidentified propulsion mechanism while surprisingly lacking apparent flagella systems [42]. Mechanisms such as the expulsion of a Newtonian fluid were excluded early on and instead a swimming mechanism was proposed to resemble the helical rotor mechanism propelling myxobacteria [96]. However, the involvement of MreB in cyanobacterial motility has so far not been demonstrated. 


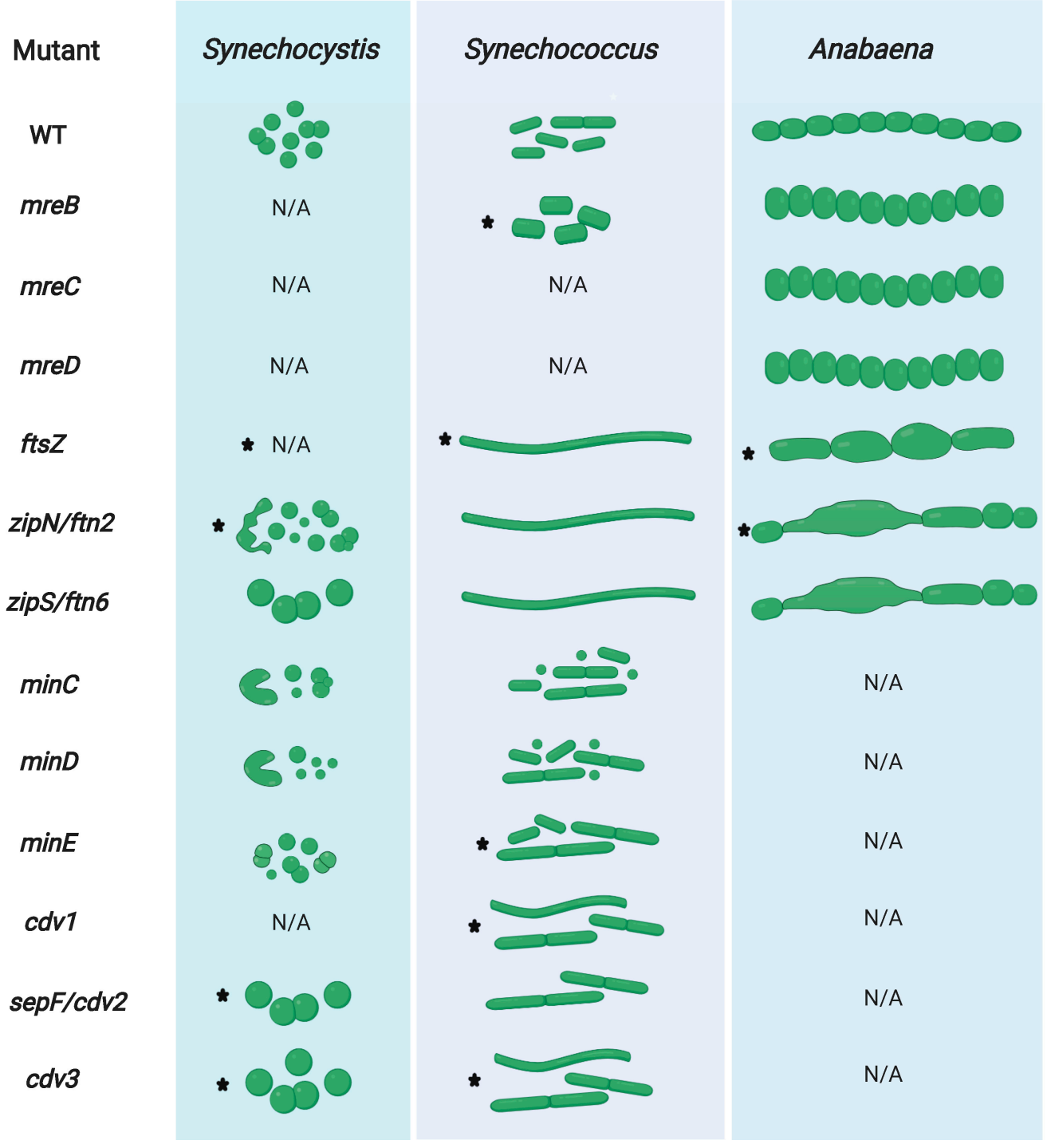

Figure 1. Cyanobacterial cell division and cell growth mutant phenotypes in Synechocystis, Synechococcus, and Anabaena. Stars indicate gene essentiality in the respective organism. Of note: while one gene can be essential in one cyanobacterial organism/morphotype, it does not necessarily mean it is essential in all other cyanobacteria. N/A indicates that no mutant phenotypes have been described. WT: wild type. Image created with BioRender.com. WT [19]; mreB [58,81,83,84]; mreC [58]; mreD [58]; ftsZ [86,87]; zipN/ftn2 [86,88,89]; zipS/ftn6 [86,89,90]; $\operatorname{minC}$ [88,91]; $\operatorname{minD}[88,91] ; \operatorname{minE}$ [88,91]; cdv1 [86]; sepF/cdv2 [86,90]; cdv3 [86,92].

\subsection{Different Modes of Cell Shape Regulation in Cyanobacteria}

Despite their morphological complexity, cyanobacteria contain all conserved and so far known bacterial morphogens (Table 1). Understanding cyanobacterial morphogenesis is challenging, as there are numerous morphotypes among cyanobacterial taxa, which can also vary within a given strain during its life cycle [19]. Changes in cellular or even trichome morphologies are tasks that would require active cell wall remodeling and thus far no genes attributed to the different morphotypes have been identified in cyanobacteria [20]. Therefore, the most likely scenario is that genes or their products are differentially regulated during these cell morphology transitions [22], as it has been hypothesized for most bacteria [62]. In multicellular cyanobacteria, division of labor between cells within a trichome is achieved by different cell programing strategies. Thus, gene regulation occurs differentially in these specific cell types $[30,97,98]$. 
Table 1. Proteins involved in cyanobacterial cell division and cell morphology.

\begin{tabular}{|c|c|c|c|c|}
\hline \multirow[b]{2}{*}{ Proteins } & \multicolumn{3}{|c|}{ Cyanobase Locus Tags and NCBI Accession Numbers } & \multirow[b]{2}{*}{ Function } \\
\hline & Synechocystis & Synechococcus & Anabaena & \\
\hline FtsZ & Sll1633 (WP_010872126.1) & Synpcc7942_2378 (WP_011244037.1) & Alr3858 (WP_010997999.1) & Cell division \\
\hline $\mathrm{ZipN}(\mathrm{Ftn} 2)$ & Sll0169(WP_010873289.1) & Synpcc7942_1943 (WP_011244461.1) & All2707 (WP_010996860.1) & Cell division \\
\hline ZipS (Ftn6) & Sll1939 (WP_010871735.1) & Synpcc7942_1707 (WP_011244694.1) & All1616 (BAB77982.1) & Cell division \\
\hline Cdv1 & Sll0227 (WP_010871341.1) & Synpcc7942_0653 (WP_011243187.1) & All4287 (BAB75986.1) & Cell division \\
\hline SepF (Cdv2) & Slr2073 (WP_010872037.1) & Synpcc7942_2059 (WP_011378295.1) & Alr0487 (WP_010994663.1) & Cell division \\
\hline Cdv3 & Slr0848 (WP_010873766.1) & Synpcc7942_2006 (WP_011244399.1) & Alr4701 (WP_010998832.1) & Cell division \\
\hline YlmD & Slr1573 (WP_010874196.1) ${ }^{a}$ & Synpcc7942_0346 (WP_011243479.1) & All5255 (WP_010999379.1) & Cell wall synthesis \\
\hline \multirow[t]{2}{*}{ YlmG } & Ssr2142 (WP_010871471.1) & Synpcc7942_0477 (WP_011243354.1) $\mathrm{b}$ & Asl2061 (WP_010996222.1) & Cell division \\
\hline & Ssl0353 (WP_010873648.1) & Synpcc7942_2017 (WP_011244388.1) & Asl0940 (WP_010995114.1) & \\
\hline YlmH & Sll1252(WP_010872783.1) ${ }^{\mathrm{c}}$ & Synpcc7942_1503(WP_011378057.1) ${ }^{\mathrm{c}}$ & Alr2890 (WP_010997041.1) ${ }^{\mathrm{c}}$ & Unknown \\
\hline MinC & Sl10288 (WP_010873891.1) & Synpcc7942_2001 (ABB58031.1) & Alr3455 (BAB75154.1) & Cell division \\
\hline \multirow[t]{3}{*}{ MinD } & Sll0289 (WP_010873890.1) & Synpcc7942_0896 (WP_011242956.1) ${ }^{d}$ & Alr3456 (WP_010997606.1) $\mathrm{e}^{\mathrm{e}}$ & Cell division \\
\hline & - & Synpcc7942_0220 (WP_011243604.1) & All2033 (WP_010996194.1) & \\
\hline & - & - & All2797 (WP_010996948.1) & \\
\hline $\operatorname{MinE}$ & Ssl0546 (WP_010873889.1) & Synpcc7942_0897 (WP_011242955.1) & Asr3457 (WP_010997607.1) & Cell division \\
\hline SulA & Slr1223 (WP_014407090.1) & Synpcc7942_2477 (WP_011243937.1) & All2390 (WP_010996546.1) & Cell division \\
\hline FtsI & Sll1833 (WP_010871772.1) & Synpcc7942_0482 (WP_011243349.1) & Alr0718 (WP_010994893.1) $\mathrm{g}$ & Cell division \\
\hline \multirow[t]{2}{*}{ FtsK/SpoIIIE } & Sll0284 (WP_010873902.1) ${ }^{\mathrm{h}}$ & Synpcc7942_0981 (WP_011242875.1) $\mathrm{h}$ & Alr3799 (WP_010997940.1) $\mathrm{h}$ & Cell division \\
\hline & - & - & All7666 (WP_010993994.1) ${ }^{\mathrm{i}}$ & \\
\hline FtsN & Slr0702 (WP_010873961.1) & N/A & $\mathrm{N} / \mathrm{A}$ & Cell division \\
\hline FtsQ & Sll1632 (WP_010872127.1) & Synpcc7942_2377 (WP_011378434.1) & Alr3857 (WP_010997998.1) & Cell division \\
\hline FtsW & Slr1267 (WP_010872891.1) & Synpcc7942_0324 (WP_011377535.1) & All0154 (WP_010994331.1) & Cell division \\
\hline Fts $X$ & $\mathrm{~N} / \mathrm{A}$ & N/A & All1757 (WP_010995925.1) & Cell division \\
\hline CyDiv & N/A & N/A & All2320 (WP_010996476.1) & Cell division \\
\hline SepI & $\mathrm{N} / \mathrm{A}$ & $\mathrm{N} / \mathrm{A}$ & Alr3364 (BAB75063.1) j & Cell-cell contact \\
\hline $\operatorname{RodA}$ & $\mathrm{N} / \mathrm{A}$ & Synpcc7942_1104 (WP_011377865.1) & Alr0653 (WP_010994829.1) & Cell elongation \\
\hline MreB & $\mathrm{N} / \mathrm{A}$ & Synpcc7942_0300 (WP_011243524.1) & All0087 (BAB77611.1) & Cell elongation \\
\hline MreC & $\mathrm{N} / \mathrm{A}$ & Synpcc7942_0299 (WP_011243525.1) & All0086 (WP_010994263.1) & Cell elongation \\
\hline MreD & $\mathrm{N} / \mathrm{A}$ & Synpcc7942_0298 (ABB56330.1) & All0085 (BAB77609.1) & Cell elongation \\
\hline BolA & Ssr3122 (WP_010871705.1) & Synpcc7942_1146 (ABB57176.1) & Asr0798 (WP_010994972.1) & Cell elongation \\
\hline
\end{tabular}


Table 1. Cont

\begin{tabular}{|c|c|c|c|c|}
\hline \multirow[b]{2}{*}{ Proteins } & \multicolumn{3}{|c|}{ Cyanobase Locus Tags and NCBI Accession Numbers } & \multirow[b]{2}{*}{ Function } \\
\hline & Synechocystis & Synechococcus & Anabaena & \\
\hline CikA & Slr1969 (WP_010872820.1) & Synpcc7942_0644 (WP_011243194.1) & All1688 (WP_010995857.1) & Circadian rhythm \\
\hline PBP1 & S110002 (WP_010873436.1) & Synpcc7942_2000 (WP_011378270.1) & Alr5101 (WP_010999227.1) & Cell wall synthesis \\
\hline PBP2 & Slr1710 (WP_010871874.1) & Synpcc7942_0785 (ABB56817.1) & Alr4579 (WP_010998711.1) & Cell wall synthesis \\
\hline PBP3 & Sll1434 (WP_010872930.1) & Synpcc7942_2571 (WP_011243849.1) & All2981 (WP_010997132.1) & Cell wall synthesis \\
\hline PBP4 & Sll1833 (WP_010871772.1) & Synpcc7942_0580 (WP_011377631.1) & Alr5326 (BAB77025.1) & Cell wall synthesis \\
\hline PBP5 & Slr0646 (WP_010873596.1) & Synpcc7942_1934 (ABB57964.1) & Alr5324 (WP_010999448.1) & Cell wall synthesis \\
\hline PBP6 & Sll1167 (WP_010872913.1) & Synpcc7942_0482 (WP_011243349.1) & All2981 (WP_010997132.1) & Cell wall synthesis \\
\hline PBP7 & Slr1924 (WP_010873199.1) & N/A & Alr5045 (WP_010999171.1) & Cell wall synthesis \\
\hline PBP8 & Slr0804 (WP_010872730.1) & $\mathrm{N} / \mathrm{A}$ & Alr0718 (WP_010994893.1) $\mathrm{g}$ & Cell wall synthesis \\
\hline PBP9 & N/A & $\mathrm{N} / \mathrm{A}$ & Alr0153 (WP_010994330.1) & Cell wall synthesis \\
\hline PBP10 & N/A & N/A & Alr1666 (WP_010995835.1) & Cell wall synthesis \\
\hline PBP11 & $\mathrm{N} / \mathrm{A}$ & $\mathrm{N} / \mathrm{A}$ & Alr0054 (WP_010994231.1) & Cell wall synthesis \\
\hline PBP12 & N/A & N/A & All2656 (WP_010996812.1) & Cell wall synthesis \\
\hline
\end{tabular}

Absent in cyanobacteria according to [28,86,88]: FtsA, FtsB, ZapA, ZapB, ZapC, ZipA, EzrA, FtsB, FtsL, FtsN (although FtsN was reported in Synechocystis by [92]). a: Note that [92] identified Slr1593 as YlmD homolog, while we found this protein to be not the closest relative to YlmD from Bacillus subtilis or Staphylococcus aureus YlmD. b: YlmG as identified by [99]. c: predicted as photosystem II S4 domain protein. d: MinD identified by [100]; 27.5\% sequence identity to Synpcc7942_0220. e: Anabaena MinD sequence identities: Alr3456+All2033: 23.1\%; Alr3456+All2797: 25.9\%; All2033+All2797: 59.4\%. f: No FtsE was predicted in Synechocystis and Synechococcus elongatus according to [86]. g: Identified as FtsI by [101]. h: Predicted as YjgR family proteins of the HerA clade, relatives of FtsK [102]. i: Present on the Anabaena plasmid pCC7120beta. j: CyDiv is proposed to be part of an essential late divisome protein complex [103]. N/A: not available. Note: Differences in identified penicillin-binding proteins (PBPs) were found between [92,101,104,105]. Here, we present the data from [104] as it presents the most comprehensive analysis of cyanobacterial PBPs. "-" indicates absence of additional homologs. 
The multiplicity of mechanisms and life strategies displayed by cyanobacteria such as photosynthetic lifestyle, the presence of thylakoid membranes (with the exception of Gloeobacter [106]), carboxysome assembly, motility, nitrogen fixation and cell differentiation (i.e., hormogonia, akinetes, heterocysts and necridia) are associated with specific regulatory mechanisms that coordinate the different processes $[30,97,98,107-111]$. These regulatory mechanisms are complex and often intricate. Given this vast regulatory network, mutations that affect processes such as cell wall synthesis $[26,101,105,112,113]$, intercellular transport $[114,115]$ and cell division $[88,90,116,117]$ may alter cell shape. Consequently, the function of the $m r e B$ gene or the entire mreBCD operon $[58,84]$ was analyzed in gene overexpression or gene deletion mutants of these aforementioned processes (reviewed by [59]). In all studied cases, upregulation of $m r e B$ is associated with the transition from coccoid to rod shaped cells. MreB is also involved in the morphological transition during N. punctiforme hormogonia differentiation. Transcriptomic studies revealed that $m r e B$ and $\operatorname{rod} A$ were both upregulated in hormogonia from N. punctiforme. Similar to M. laminosus hormogonia [118], N. punctiforme hormogonia are characterized for having a smaller cell size and rod-shape in comparison with the larger and more coccoid cells of the mature trichome. Upregulation of $m r e B$ was also observed in a "branchless" morphotype of F. muscicola induced under sucrose supplementation [22], indicating that environmental growth conditions play a crucial role in cell shape regulation. Branch-less cultures were characterized by long trichomes that appear as nascent hormogonia previous to the detachment from the parent trichome $[19,22]$. Cells in the branchless cultures are longer, narrower and display a rod shape with tapered cells at the tip of the trichome compared to the more diverse cell morphologies (e.g., elliptical, rod-shaped, coccoid-shaped) in the parent trichome [22].

As photosynthetic microorganisms, iron has a pivotal role in cyanobacterial photosynthesis and defense against oxidative stress [119]. The transcriptional regulator FurA has been demonstrated as the master regulator of iron homeostasis in Anabaena [120] and was also shown to be involved in several other processes such as heterocyst differentiation and programmed cell death [119]. Overexpression of FurA in Anabaena lead to alterations in the cell shape, possibly through its positive regulatory function of the $m r e B C D$ operon [121]. Another prominent environmental factor affecting cyanobacterial cell shape is the availability of fixed nitrogen sources. Similar to the essential cell division gene $\mathrm{fts} Z$ (discussed further below), $m r e B$ is differentially regulated during heterocyst formation [84]. Unlike ftsZ, mreB is upregulated during heterocyst formation in Anabaena pro-heterocysts [84,97] and an N-terminally GFP-tagged MreB localized to the cell poles in both vegetative cells and heterocysts [84]. The increase in MreB levels during heterocyst formation possibly provides the framework for the increase in cell size, which requires de-novo synthesis and integration of PG into the cell wall. In agreement with this, a recent study found that the incorporation of fluorescently labelled amino acids [122] into the Anabaena cell wall was elevated during heterocyst maturation [123]. PG biosynthesis enzymes, which are associated with the MreB-driven elongasome $[68,124]$, were furthermore identified by several different groups to be essential for heterocyst formation $[13,125,126]$, strengthening the importance of MreB function for heterocyst development. Additionally, mreB and mreC but not $m r e D$ are essential for diazotrophic growth of Anabaena, with a supposable function subsequent to heterocyst formation as Anabaena mreB, mreC and mreD mutants still differentiated heterocysts [58]. In the Anabaena wild type, cells are shorter during diazotrophic growth and longer in the presence of combined nitrogen [58]. This phenomenon can be explained by an increase in the levels of the global transcriptional regulator $\mathrm{NtcA}$ during diazotrophic growth. NtcA negatively regulates the mreBCD operon, leading to a reduced cell length. Consistently, an $n t c A$ deletion mutant was characterized by an increased cell length [58].

Other factors that might regulate cell shape in cyanobacteria could be the interplay between the FtsZ and MreB cytoskeleton. In E. coli FtsZ and MreB can physically interact and this interaction is important for the progression from cell growth to cell division [127], whereas no direct effect of MreB on Z-ring placement and septum formation was observed in Anabaena [84]. This finding is in concert with the lack of interaction between MreB and FtsZ in Anabaena [77]. Notably, we recently showed that in the complex multicellular cyanobacteria F. muscicola and Chlorogloeopsis fritschii PCC 6912, 
MreB physically interacted with FtsZ [77], suggesting that their complex trichome and cell phenotypes could, in part, rely on the crosstalk between the elongasome and the FtsZ-driven divisome.

\section{The Cyanobacterial Cell Division Complex-Function and Regulation}

Numerous studies over the past years have conclusively shown that cyanobacteria not only possess a hybrid Gram phenotype in terms of their cell envelope but also possess proteinaceous structural determinants otherwise restricted to a single Gram type. The processes of PG and cell wall remodeling as well as cell septation rely on other divisome components that are recruited to the Z-ring. The Z-ring functions as a scaffolding structure for other divisome components but also potentially exerts constrictive force as indicated by FtsZ's ability to bend liposomes [128,129]. In E. coli, more than 30 proteins have been identified as divisome or divisome-associated components, among those, 12 are essential and commonly associated with the divisome in the order: FtsZ $\rightarrow$ FtsA/ZipA $\rightarrow$ FtsE/FtsX $\rightarrow$ FtsK $\rightarrow$ FtsQ/FtsL/FtsB $\rightarrow$ FtsW/FtsI $\rightarrow$ FtsN (for reviews on bacterial cell division processes, please see $[68,130,131])$. The arrival of FtsN primes the divisome for septal PG synthesis and cell division. Homologs to some of those divisome proteins have been identified in cyanobacteria, including FtsE, FtsQ, FtsW and FtsI, while FtsA, ZipA, FtsL and FtsB are absent in cyanobacteria $[28,86,88]$. Other divisome-associated proteins from E. coli or Bacillus subtilis are likewise absent in cyanobacteria, including ZapA, ZapB, ZapC and EzrA. With one exception identified in Synechocystis [92], FtsN cannot be found in cyanobacteria. Similarly, a FtsX and FtsK homolog was so far only identified in Anabaena [86,132]. In agreement with their enormous morphological diversity, several morphological determinants specific to the Cyanobacteria phylum were also described, among those Ftn2 (ZipN) and Ftn6 (ZipS) [88-90,92,132-134]. Given the nonuniform nomenclature of cyanobacterial protein identifiers and to ease future research on cyanobacterial morphologies, we have collected a comprehensive list of important cyanobacterial structural determinants from the three widely used cyanobacteria Anabaena, Synechocystis and Synechococcus (Table 1). In the following sections, we will further elucidate the currently available information on some of those proteins, including their cellular context and functional properties.

\subsection{Polymerization Properties of Cyanobacterial FtsZ}

Cell division in bacteria is, with a few exceptions, strictly dependent on the function of the tubulin homolog FtsZ and its associated multiprotein complex, termed the divisome. FtsZ is an essential and highly conserved GTPase in almost all bacteria, Euryarchaeota, photosynthetic eukaryotes (i.e., in their chloroplasts) and even in some mitochondria [4,5,12,135-137]. Upon completion of chromosome segregation, FtsZ is the first protein to assemble at the future division site, forming a ring-like structure (the Z-ring) through GTP-dependent polymerization of FtsZ monomers into short protofilaments. Both, Anabaena and Synechocystis FtsZ contain the conserved glycine-rich GTP-binding domain, which is crucial for in vivo Z-ring formation and in vitro polymerization [88,138-140]. Unlike other bacterial FtsZ proteins, purified Synechocystis FtsZ assembles into a mixture of straight bundles, similar to chloroplast FtsZ, and toroidal filaments, indicating that the curved cyanobacterial FtsZ polymers could bend the cytoplasmic membrane $[139,140]$. Many cyanobacteria contain a highly variable $\mathrm{N}$-terminal sequence extension of the FtsZ protein (between 20 and 80 amino acids long) that is absent in other bacteria but strikingly conserved among heterocystous cyanobacteria [88,140]. The N-terminal sequence is essential for Anabaena viability and, although FtsZ and an N-terminally truncated FtsZ ( $\Delta$ N-FtsZ) interact with each other, a $\Delta N$-FtsZ-GFP fusion protein could not integrate into native Z-rings, possibly a result of its inability to interact with the FtsZ membrane anchor SepF $[140,141]$. While native Anabaena FtsZ forms toroids in vitro, $\triangle \mathrm{N}$-FtsZ only associates into filament bundles. As a consequence, the $\mathrm{N}$-terminal peptide of Anabaena FtsZ, and possibly that of other cyanobacteria, likely promotes filament curling and decreases lateral filament bundling [140]. FtsZ filament curling or toroid-formation in Anabaena and Synechocystis FtsZ supports a constriction force of the cyanobacterial Z-ring itself, which is also 
described for E. coli FtsZ [139,142]. However, studies on Prochlorococcus Z-ring assembly suggest that it is likely not contractile in this species and possibly merely functions as a scaffold in oval-shaped cyanobacteria [143]. Straight filament bundles and toroids were previously reported for E. coli and M. tuberculosis FtsZ but only in the presence of crowding agents such as methylcellulose or polyvinyl alcohol. Given the larger cell diameter of Synechocystis and Anabaena $(2-3 \mu \mathrm{m})$, filament bundling could be beneficial for their increased cell size compared to, for example, rod-shaped E. coli or Synechococcus, which are considerably smaller $(1 \mu \mathrm{m}$ cell diameter). Whether filament bundling exists in filamentous cyanobacteria with diameters less than $1 \mu \mathrm{m}$ such as species of the genus Halomicronema [144] remains yet to be investigated. Many small rod-shaped bacteria also lack a signature motif in the H8 helix, which is likely responsible for filament bundling $[139,140]$. Consequently, cell shape possibly poses an evolutionary constraint on the functional diversification of proteins important for cell division. Considering the different cyanobacterial morphotypes, it will be interesting to test whether a similar observation also exists for processes that regulate cell growth in cyanobacteria, i.e., for the cell shape determining protein MreB.

\subsection{FtsZ is Essential in Cyanobacteria}

In cyanobacteria, fts $Z$ homologs were detected in every sequenced species and $f t s Z$ was found to be essential in Anabaena, Synechocystis and Synechococcus $[86,88,138,145]$. Partial inactivation of $\mathrm{ftsZ}$ or addition of a tubulin assembly inhibitor (thiabendazole) causes cell filamentation (elongation) in the rod-shaped E. coli and Synechococcus and cell swelling in the coccoid Synechocystis [145]. Contrasting this, partial depletion of $f t s Z$ or overexpression of the FtsZ assembly inhibitor min $C$ results in a mixed filamentous/elongated and swollen cell shape in Anabaena $[87,116]$ (Figure 1). Given that the ellipsoid cell shape of Anabaena can be considered a hybrid phenotype between the coccoid and rod-shape phenotype of Synechocystis and Synechococcus, formation of a hybrid cell shape defect upon impairment of cell division seems consistent. In the baeocytes-forming subsection II cyanobacterium Chroococcidiopsis sp. CCMEE 029, ftsZ is also essential and partial deletion disrupts the regularity in daughter cell arrangements, leading to cell aggregates. These aggregates, however, did not enlarge in cell volume compared to the wild type [146]. Therefore, the impact of impaired cell division appears to be highly dependent on the respective cyanobacterial morphotype and could result in different shapes in other so far understudied cyanobacterial subsections.

\subsection{Cellular Localization of FtsZ in Cyanobacteria}

As in other bacteria, FtsZ localizes to the middle of the cell in cyanobacteria, forming the typical Z-ring structure $[86,88,116]$. Consecutive Z-rings from neighbouring cells in the Anabaena trichome align parallel to each other. Z-rings from deeply-constricted Synechocystis daughter cells, however, form Z-rings that are perpendicular to each other [116], reminiscent of what we observed for true-branching subsection V cyanobacteria [77]. Using photobleaching of cyanobacterial autofluorescence coupled to super-resolution microscopy (STORM; stochastic optical reconstruction microscopy) of the unicellular, coccoid-shaped Prochlorococcus sp. MED4, a lateral resolution of $10 \mathrm{~nm}$ of Z-ring assembly was achieved [143]. Liu and colleagues found that FtsZ rings all contained small gaps, being non-continuous assemblies, and that FtsZ first polymerizes into incomplete and then complete rings, resembling the observations from E. coli. Consequently, their study thus supports the so-called patchy band model, where FtsZ assembles into discontinuous strings during cell division in contrast to the lateral association model that states that FtsZ polymers interact laterally to assemble into a complete Z-ring [143]. Studying other cyanobacterial morphotypes could consequently shed more light onto the debate about the FtsZ polymerization mechanisms in bacteria and might even indicate different assembly properties based on different cell shapes. 


\subsection{Transcriptional and Posttranslational Control of Cell Division in Cyanobacteria}

E. coli ftsZ is transcribed in an operon together with $f t s A$ (absent in cyanobacteria) and fts $Q$ (i.e., the $f t s Q A Z$ operon), whereas no $f t s Q Z$ operon was observed in Anabaena, Synechocystis nor Synechococcus, where ftsZ is independently transcribed from $f t s Q$ instead $[109,147]$, contrasting the identified $f t s Q Z$ operon structure in $M$. aeruginosa [148]. Given that cyanobacteria are photosynthetic organisms, it is not surprising that cell division and consequently fts $Z$ expression patterns are dependent on the circadian clock with an expression peak near dusk in Synechococcus and Synechocystis $[147,149]$. This circadian rhythmicity in Synechococcus is governed by the essential circadian clock protein kinase KaiC, through inhibition of Z-ring formation without impacting the cellular FtsZ protein levels [150]. In contrast, fts $Z$ transcription and cell division occur during the light cycle in the diazotrophic (nitrogen-fixing), unicellular Cyanothece sp. ATCC 51142 [151]. Diurnal control of ftsZ transcription also occurs in the marine, filamentous and nitrogen-fixing T. erythraeum IMS101. There, cell division and cell differentiation (into nitrogen-fixing diazocytes) occurs early during the dark period, which is preceded by an upregulation of $f t s Z$ expression (and FtsZ protein level) [151]. Reminiscent of the dependency of cell division for heterocyst-development in Anabaena [152], diazocyte-development could be dependent on cell division in T. erythraeum [151]. Consequently, cell differentiation in cyanobacteria appears to be strongly connected to cell division and is halted in differentiated cells through a downregulation of $f t s Z$ transcription and/or a decrease in FtsZ protein levels [116,153-155]. This notion is supported by the absence of Z-rings in terminally differentiated mature heterocysts in Anabaena $[19,116,133]$. Notably, loss of Z-rings precedes loss of detectable $f t s Z$ transcripts, with the former taking place in immature heterocysts and the latter in mature heterocysts [133]. Thus, FtsZ is a cell division factor specific to vegetative cells in Anabaena [155]. The arrested cell division after heterocyst development is also apparent in true-branching filamentous cyanobacteria such as M. laminosus and other Fischerella species. During the life cycle the initially narrow trichomes with cylindrically shaped cells mature to wide trichomes with coccoid cells that give rise to true branches of cylindrical cells $[52,156]$. Once a heterocyst has formed within a certain type of trichome its morphology remains unchanged even when neighboring vegetative cells undergo the maturing process. An intriguing hypothesis is that in heterocysts, proteolytic FtsZ degradation is specifically increased, thus abolishing Z-ring formations (i.e., cell division). Although not shown to be specific to or increased in heterocysts, FtsZ-specific proteases were discovered in Anabaena, F. muscicola and C. fritschii cell extracts but not in the extracts of the non-cell differentiating Synechocystis or E. coli $[77,157]$. The precise nature of these proteases remains unknown but it was found to only cleave natively folded FtsZ in Anabaena, thus being structure and not sequence-specific [157]. Recently, PatA, a protein involved in the differentiation of intercalary heterocysts under nitrogen-deprived growth conditions and that localizes to the Z-ring and the cell poles [133], was found to function in destabilizing the Z-ring in Anabaena [133]. PatA interacts with ZipN and SepF, two crucial cyanobacterial cell division factors (discussed in more detail below) and it was hypothesized that this interaction ultimately promotes the loss of Z-ring structures during heterocysts development (Figure 1). Thus, PatA could be one component responsible for the loss of Z-ring structures in immature heterocysts, ultimately promoting cell differentiation progression [133]. In T. erythraeum, ftsZ transcription occurs only after DNA replication (extrapolated from dnaA gene expression) [151] as it was also shown in the unicellular, bloom-forming cyanobacterium Microcystis aeruginosa NIES298. There, ftsZ expression is repressed upon halt of DNA replication, suggesting that there are factors in the cell that sense the DNA content and regulate $f t s Z$ transcription in response [148]. Synechococcus cells in stationary phase cultures rarely divide and elongate instead, largely due to the inhibition of DNA replication and consistent with a requirement of DNA biosynthesis for cell division [158]. Similar observations were also made for Synechocystis cultures in the stationary phase that revealed 4 to 10 times lower $f t s Z$ transcript levels compared to log phase cultures; a mechanism that has been linked to cell density sensing [149]. In Synechocystis, two transcription factors (S110822 and Sl10359), which regulate $f t s Z$ and $f t s Q$ transcription, belong to the cyAbrB clade B of transcriptional regulators. Deletion of sll0822 results in a cell division defect with swollen cells [159], similar to the Synechocystis 
ftsZ depletion strain [145]. In Anabaena, the cyAbrB transcriptional regulator CalA specifically regulates $f t s Z$ expression in vegetative cells [160]. Whether the regulation of $f t s Z$ expression by those transcription factors results in response to DNA content or other factors remains to be elucidated. Studies in Anabaena and Synechococcus have independently highlighted a positive correlation of DNA content with cell size and not with cell division, indicating that some cyanobacteria can sense their cell volume and adapt their chromosome content accordingly $[116,161,162]$. Consequently, it is conceivable that not FtsZ but MreB is indirectly involved in chromosome copy number determination, possibly through its regulatory function on cell shape and size. It is worth noting that the overall protein concentration within Synechococcus cells remained constant, regardless of the growth rate and is positively correlated with cell volume and DNA content [100].

\subsection{FtsZ-Associated Regulators Control Cell Division in Cyanobacteria}

In E. coli and B. subtilis, a number of factors, including the Zap proteins (ZapA/B/C/D) crosslink FtsZ polymers with each other or to the chromosome ends. The actin homolog FtsA, which, like FtsZ, is capable of filamentous assembly [163,164], and ZipA are major contributors of the first stage of Z-ring assembly. They anchor FtsZ to the cytoplasmic membrane through their interactions with FtsZ's C-terminal peptide (CCTP) (reviewed by [165]). Both, ZipA and FtsA regulate divisome dynamics and recruit downstream divisome components to the Z-ring [166]. While FtsA is essential in E. coli, it can be deleted in B. subtilis, which results in filamentous cells that reveal a disturbed Z-ring formation [167]. Cyanobacteria lack ZipA, FtsA, ZapA and EzrA (a presumed Gram-positive-specific FtsZ membrane anchor [68]) homologs [86,148] and instead contain the cyanobacterial-specific protein ZipS (also known as Ftn6; [89]) and the cyanobacterial and plant-specific protein ZipN (also known as Ftn2) [92,132] (for a current model of the Anabaena divisome see Figure 2). Additionally, cyanobacteria possess SepF (also termed YlmF or Cdv2 [86]), a protein otherwise restricted to Gram-positive bacteria [168]. ZipN, ZipS and SepF all localize to the midcell in Synechocystis $[88,90]$ suggesting that all three are important factors of the cell division machinery. They are, however, characterized by different levels of essentiality, depending on the respective cyanobacterial morphotype. sepF is essential in Synechococcus and Synechocystis [86,90], zipN is dispensable for Synechococcus but is essential in Synechocystis and Anabaena $[88,89,132]$, whereas zipS can be deleted in Synechococcus and Anabaena but not in Synechocystis [89]. This inconsistency could reflect adaptations of the specific proteins to the respective morphology of its host.

SepF from B. subtilis is recruited early to the Z-ring and functions as a specific FtsZ membrane anchor, regulating the late septum formation [141,168]. In E. coli, FtsA or ZipA alone are sufficient to establish Z-ring anchorage to the cytoplasmic membrane, which is only lost upon simultaneous deletion of both [166]. The situation seems to be quite a bit more complex in cyanobacteria, possibly a result of the hybrid Gram phenotype and the morphological diversity. ZipN and its plant homolog ARC6 [169] contain a C-terminal transmembrane domain potentially suitable for membrane attachment [92,132], reminiscent of the amphipathic helix that mediates membrane localization of FtsA [165]. Furthermore, ZipN homologs contain a chaperone-like N-terminal DnaJ domain and a tetratricopeptide repeat (TPR) domain, suggesting that ZipN could function in mediating protein-protein interactions and/or affect protein folding [89]. Indeed, ZipN interacts with FtsZ in vitro and localizes to the Z-ring in Synechocystis and Anabaena (see Figure 2) [112,133], which is likely mediated by the DnaJ domain of $\mathrm{ZipN}$, as removal of this domain results in diffuse cytoplasmic GFP-ZipN signals [112]. Reminiscent of FtsAs' function in E. coli, ZipN is able to self-interact and functions as a de novo anchor of FtsZ to the cytoplasmic membrane in cyanobacteria [92,132]. Similar to E. coli FtsA, B. subtilis SepF assembles into round protein filaments and associates and bundles with FtsZ filaments in vitro [170]. Synechocystis SepF and ZipS directly interact with FtsZ filaments in vitro but only SepF is able to stimulate the assembly of FtsZ filaments [90]. Based on these observations, it was suggested that ZipS functions downstream of SepF, i.e., after the Z-ring is functionally assembled [90]. 


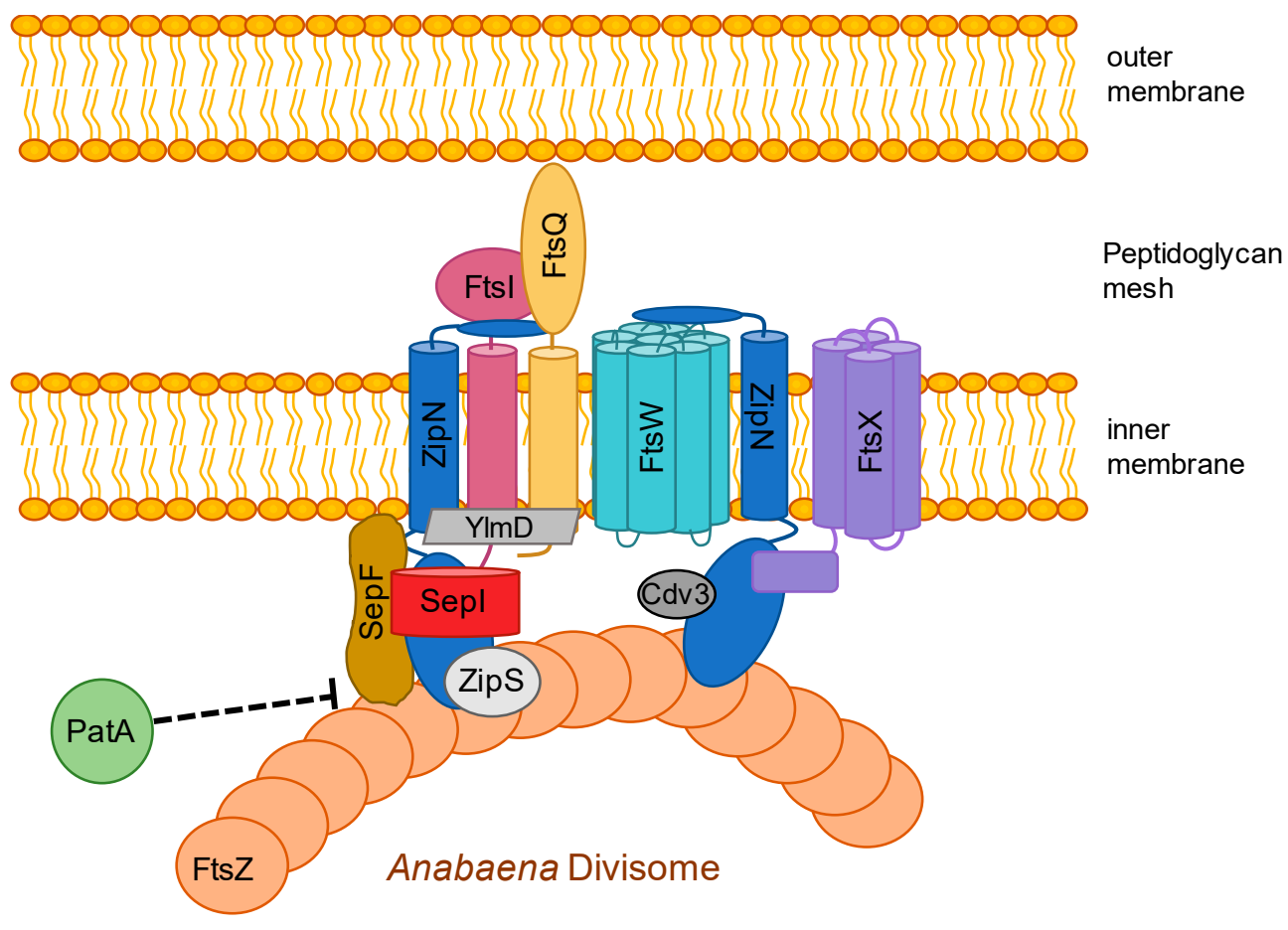

Figure 2. Proposed model of the Anabaena divisome. Proteins in grey shades are inferred from a previous model described for Synechocystis [92]. PatA is assumed to negatively interfere with the linkage of FtsZ to the cytoplasmic membrane through the loss of interaction with its presumed cytoplasmic membrane anchors SepF and ZipN.

A direct function of SepF or ZipS in FtsZ membrane anchoring has not yet been described and depletion of sepF and zipS did not affect Z-ring formation but considerably altered the Z-ring structure and delayed cytokinesis, leading to swollen Synechocystis cells [90] (Figure 1). In the coccoid Synechocystis, zipN is required for normal cytokinesis and a zipN-depleted strain formed minicells or spiral-shaped cells [62] (see also Figure 1). Deletion of zipN and zipS but not depletion of sepF abrogates Z-ring formation in Synechococcus, leading to a patchy and diffuse pattern of FtsZ at the septum site [86], suggesting functional differences of zipS and zipN between the rod-shaped Synechococcus and the coccoid Synechocystis. Similar to the filamentous B. subtilis sepF mutant [168], rod-shaped Synechococcus cells deleted of $z i p N$ or zipS or depleted of sepF became filamentous or elongated $[86,89]$. Filamentous Synechococcus zipN or zipS mutants divided irregularly and can be up to 100 or 20 times longer than wild type Synechococcus, respectively [89]. Using light microscopy, both mutants appeared normal, however, ultrastructural analysis using scanning and transmission electron microscopy discovered that they are characterized by irregular cell bending and spiralization and have a decreased cell wall rigidity that is not a result of a PG layer defect [134]. None of this, however, affected the growth rate of the zipN and zipS Synechococcus mutants [89]. In the multicellular, ellipsoid-shaped Anabaena, zipN is essential while zipS can be deleted and both depletion of $z i p N$ or deletion of $z i p S$ lead to aberrant elongated and swollen Anabaena cells $[89,132]$. Thus, it seems that in those strains cell division but not cell growth is impaired. Confirming this, FtsZ was found to localize in a patchy and delocalized pattern around the cell division septa in the zipN and zipS Synechococcus mutants [86]. Likewise, depletion of $z i p N$ leads to a delocalization of FtsZ and a loss of Z-ring formation in Anabaena, implying a dysfunctional Z-ring assembly in strains lacking zipN [132].

The observation of swollen (Synechocystis, Anabaena) or filamentous (Synechococcus, Anabaena and E. coli) cells for the respective cell division mutants (for a depiction of several cyanobacterial cell division and cell shape mutant phenotypes see Figure 1) is considered to occur when cell septation is slowed down (or impaired) in relation to cell growth (i.e., lateral PG insertion) [4,17]. This idea is 
supported by a study that analyzed the proteome of filamentous Synechococcus cells deleted of zipN or zipS, which detected an upregulation of proteins involved in nucleotide biosynthesis like $\operatorname{dnaN}$ (DNA polymerase III beta subunit) and cell growth, including mreB [117]. As a result of the upregulation of cell-cycle-specific genes, the authors conclude that ZipN and ZipS likely act in a stage prior to cell division [117], which correlates with their occurrence early at the Z-ring during cell division in Synechocystis $[88,90]$. Notably, carboxysome-associated genes were also differentially expressed in the Synechococcus zipN and zipS mutants [117], being in concert with the observed decreased carboxysome count and the appearance of abnormal carboxysome-like structures not present in the wild type [134]. Consequently, both ZipN and ZipS have pleiotropic functions besides cell division and could be involved in carbon fixation. Given that carboxysome-segregation is dependent on McdA/B [171] and carboxysome subunit expression is affected by the deletion of zipS and zipN [117], a functional relationship between the cell division apparatus (i.e., divisome) and the carboxysome-segregation mechanism is possible and worth future investigation. More recently, ZipN was also attributed a function in cell differentiation in Anabaena. It was shown that ZipN protein levels, similar to FtsZ levels, are downregulated during heterocyst development, albeit at an earlier stage of heterocyst development (i.e., pre-heterocysts) [133]. Based on the interaction of PatA with ZipN (and SepF), the authors hypothesize that the initial binding of PatA to ZipN leads to a destabilization and loss of ZipN early during heterocyst-formation, followed by a destabilization and loss of FtsZ due to the lack of its membrane anchor (i.e., ZipN) in mature heterocysts. The subsequent downregulation of $f t s Z$ transcription then seals the fate for the irreversible cell differentiation into heterocysts [133].

Highlighting its essential role for cyanobacterial viability and morphology, ZipN was found to interact with ZipS, SepF, FtsI and FtsQ in Synechocystis and Anabaena [92,112,132,172] with FtsK, FtsW, SepJ and SepI specifically in Anabaena [87,132,172] and with Cdv3 specifically in Synechocystis [92] (Figure 2). A more condensed summary of this and other known interaction networks of morphological determinants in Synechocystis and Anabaena is also given in Figure 3. Not much is currently known about the interaction profile of SepF and ZipS in cyanobacteria and unlike the FtsZ membrane-tethering function of ZipN, the precise function of SepF and ZipS remains to be elucidated. However, given that ZipS contains an N-terminal DnaD-like domain, which is involved in DNA binding, it could putatively act to bridge DNA replication with cell division in cyanobacteria [173]. It will be interesting to see whether this assumed function might provide the functional basis explaining the lack of a nucleoid occlusion system (explained in more detail below) in cyanobacteria.

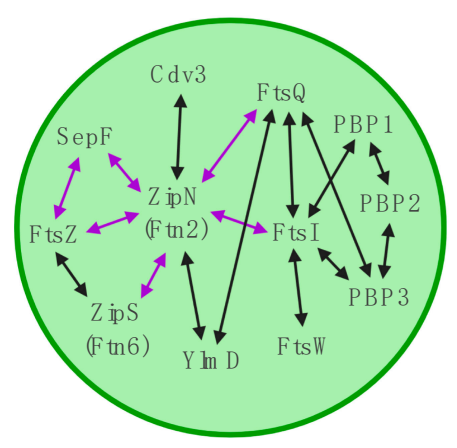

Synechocys tis sp PCC 6803

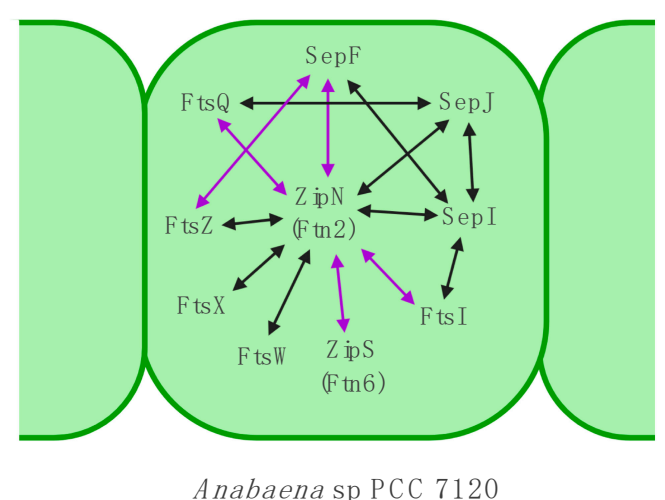

Anabaena sp PCC 7120

Figure 3. Interaction network of cell division/growth proteins in Synechocystis and Anabaena. Depiction of protein-protein interactions as identified by bacterial adenylate cyclase two hybrid assays and co-immunoprecipitation experiments. Interactions were identified in $[87,88,90,92,132,172]$. Black arrows indicate interactions solely found in one species so far, while purple arrows mark interactions found in both Synechocystis and Anabaena. Interactions only attributed to one species do not necessarily imply these interactions do not exist in the other but rather that these interactions were not yet tested for. Image created with BioRender.com. 


\subsection{The Divisome is Linked to the Sites of Cell-cell Connections in ANABAENA}

Connection of multicellular cyanobacteria, including Anabaena, is, in part, mediated by an incomplete cell division and likely also through cell-cell-joining structures between neighboring cells (reviewed in $[28,29,60])$. The latter is indicated by a trichome fragmentation phenotype of mutants of the septal-localized proteins SepJ and SepI or septal junction proteins FraC and FraD [114,115,172]. Besides septal localization, SepJ, SepI and FraC additionally localize to the midcell in rings, reminiscent of the Z-ring $[105,114,115,172,174,175]$, giving rise to the compelling connection between the cell division apparatus and the cell septa in Anabaena. This idea was followed up by numerous protein-protein interaction and fluorescent protein localization studies that revealed that, although SepJ does not interact with FtsZ, it does bind the cell division protein FtsQ [87], a bitopic membrane protein that putatively links the periplasmic to the cytoplasmic divisome proteins [176]. SepI also interacts with SepJ and with FtsI, SepF but not with FtsZ, ZipS, FraC, FraD, MreB, MinC and other Fts proteins (Figure 1) [172]. Unlike in unicellular bacteria, multicellularity in Anabaena is achieved through incomplete cleavage of the septal PG [177], hinting for a modified function and composition of the Anabaena divisome [87]. Consistent with a function of the divisome in septal junction integrity and thus Anabaena multicellularity, SepJ interacts with FtsQ and ZipN and its septal localization was largely lost in ftsZ and zipN depleted Anabaena strains, being mostly dispersed in patches [87,132]. Considering that FtsQ recruits numerous proteins to the E. coli divisome [178] and that ZipN interacts with an extensive set of divisome proteins [132], it is conceivable that both FtsQ and ZipN recruit SepJ to the Anabaena divisome, which then remains in the septa upon completed cell division $[28,87]$. Deletion of sepI, which, like sepJ, also functions in Anabaena multicellularity, nanopore formation and cell-cell communication did not alter Z-ring placement and only mildly affected cell shape and growth. These results suggest that SepI is a late divisome protein in Anabaena and its function is rather associated with septum integrity than divisome function [172]. Notably, and in contrast to the other characterized Anabaena divisome proteins, SepI was found to affect the colony morphology on agar plates. The implications of this for the growth of Anabaena in its natural habitat remain elusive.

\subsection{Z-Ring-All in One Place}

There are several main factors that function as negative regulators of and restrict Z-ring formation to the correct midcell placement [179]. They include the nucleoid occlusion (NO) system, consisting of SlmA in E. coli and Noc in B. subtilis, two chromosome-associated proteins that prevent Z-ring formation at sites occupied by DNA. Cyanobacteria lack SlmA and Noc homologs [17] and in Synechococcus, Z-rings were identified at sites occupied by chromosomal DNA, suggesting that cyanobacteria lack NO systems [86]. MipZ from C. crescentus belongs to the ParA/MinD family of ATPases and inhibits FtsZ assembly near the cell poles and the nucleoid through its association with the DNA-binding protein ParB [180]. Using bioinformatic searches, we could not identify MipZ homologs in Anabaena, Synechococcus and Synechocystis, consistent with the lack of a classical ParA/B/S-based DNA-segregation mechanism in cyanobacteria $[83,171]$. SulA, a FtsZ antagonist that sequesters FtsZ monomers and prevents Z-ring formation [181,182], is part of the SOS response as a reaction to DNA damage [179]. Homologs to SulA were identified in cyanobacteria ([86]. see also Table 1) and SulA was found to be essential in Synechocystis. Partial deletion of sulA resulted in cell division defects, prevented proper daughter cell segregation and led to cloverleaf-like cell aggregates [183]. Anabaena cells overexpressing E. coli but not Anabaena SulA became elongated, showed diminished Z-ring formations (like in E. coli), did not divide and, in accordance with an essential role of cell division for heterocyst-formation, did not differentiate heterocysts under nitrogen-deprived growth conditions [152]. The inability to differentiate heterocysts likely stems from the observation that $f t s Z$ is downregulated $24 \mathrm{~h}$ after nitrogen-deprivation while sulA is upregulated. This argues for an additive effect to limit cell division through less FtsZ protein, which is additionally sequestered by SulA to prevent Z-ring formation [154]. An inhibition of Z-ring formation is likely also promoted through inhibition of FtsZ's GTPase activity by SulA [152], which is essential for FtsZ filament-formation [184]. The Min system is the fourth known system 
that restricts the Z-ring to the midcell and works to prevent aberrant cell division planes in E. coli and B. subtilis. In E. coli, the Min system consists of three major proteins, MinC, MinD and MinE. MinC is the mechanistic antagonist to FtsZ polymerization through its interaction with the GTPase domain in FtsZ and concurrently with FtsZ's CCTP domain, thus competing with FtsA to prevent membrane anchorage of FtsZ. MinC is recruited to the plasma membrane by its interaction with MinD, a Walker A-type ATPase and member of the ParA/MinD family. MinE, in the form of a MinE ring, associates to the membrane bound MinCD, causing its detachment from the membrane and giving rise to a spatiotemporal dynamic pole-to-pole oscillation of MinCDE, which is highest at the cell poles and lowest at the midcell. This gradient of the FtsZ inhibitor MinC ultimately restricts Z-ring formation at the correct midcell location (reviewed in [185]). B. subtilis does not contain a MinE homolog and instead possesses a coiled-coil protein called DivIVA, which localizes to areas of negative curvature-the cell poles or the division site of constricting cells-and recruits MinCD through a linker protein called MinJ. Consequently, no Min oscillation exists in the Gram-positive B. subtilis but Z-ring formation is statically inhibited by MinCD and DivIVA (reviewed in [68]). So far, the functional properties of the Min system were only elucidated in Synechococcus that, besides MinCDE, also contains a DivIVA-like protein called Cdv3. While one report suggested that Cdv3 is essential for Synechococcus [86], another report more recently reported the complete deletion of $c d v 3$ [91]. Although, the lack of functional domains essential for DivIVA function (e.g., membrane curvature sensing) in Cdv3 suggests that it is likely not a direct homolog of DivIVA [91]. Nonetheless, Cdv3 homologs, like DivIVA, are absent from other Gram-negative bacteria [86]. Given that Synechococcus contains MinCDE, essential for pole-to-pole oscillation, but also contains a sophisticated thylakoid membrane system that could potentially inhibit oscillation, it was unknown whether pole-to-pole oscillation can be recapitulated in cyanobacteria. MacCready and colleagues, however, elegantly modelled the existence of Min system oscillation in Synechococcus under the prerequisite that thylakoid membranes have a minimal permeability. They further showed robust Min system oscillation that spatiotemporally restricts Z-ring placement to the midcell in Synechococcus, demonstrating that the Min system can differentiate between the cytoplasmic membrane and the thylakoid systems [91]. Notably, they found two different modes that utilizes MinC's ability to inhibit FtsZ polymerization: one dynamic, E. coli-like mode that employs dynamic MinC distribution through MinDE oscillation, although with a longer periodicity, and another, B. subtilis-like static mode in which Cdv3 and MinD recruit MinC rings adjacent to the Z-ring at the midcell position [91]. Synechococcus MinD is highly conserved and its C-terminal amphipathic helix but not the N-terminal ATPase domain is involved in membrane-targeting, while both are essential for MinD function [88]. MinE only shows low sequence similarity to E. coli MinE, and unlike in the E. coli $\min B$ operon, $\min C$ is not encoded together with $\min D E$ in Synechococcus [91]. Searching for MinD homologs, we identified one homolog in Synechocystis but two and three MinD homologs in Synechococcus and Anabaena, respectively (Table 1), raising the question of the function of the other MinD homologs. As in E. coli, minE is essential in Synechococcus [91], but non-essential in Synechocystis where deletion of minE has only a mild phenotype with rare minicell formations [88]. Although one study reported a fully segregated Synechococcus minE mutant with a $5^{\prime}$ inserted transposon, thus it is debatable whether minE is essential in Synechococcus [86]. Among the Min proteins, MinE likely functions as the essential regulator of Z-ring formation as minE depleted Synechococcus cells were filamentous and lacked clear Z-ring formation, which could still be observed in $\min C$ and $\min D$ knockout strains [91]. MinC overexpression induced cell enlargement (elongation in Synechococcus [91] and swelling in Anabaena [116]), and similar to SulA overexpression also halted cell division and cell differentiation in Anabaena [116], thus, attributing an important role of MinC in proper cell division and cell differentiation. Analogous to the situation in E. coli, $\min C$ and $\min D$ deletion causes defects in FtsZ placement resulting in a mixed population of minicells and elongated cells in Synechococcus. Analogous to this effect, a fully segregated Synechococcus $c d v 3$ mutant was also filamentous but did not form minicells [91]. In the coccoid Synechocystis, $\min C, \min D$ and $\min E$ deletion strains did not enlarge in cell volume and instead became spiral-shaped $(\triangle \min C \Delta \min D)$ or formed minicells $(\Delta \min C$, 
$\Delta \min D$ and $\Delta \min E$ ) [88], whereas depletion of $c d v 3$ produced giant cells [92] (Figure 1). This suggests that in Synechocystis, Cdv3 could be of more importance for the control of cell division (i.e., inhibition of FtsZ polymerization, indicated by swollen cells) than the MinCDE system. Hence, while the deletion of the MinCDE pathway is possible, the Cdv3/MinD pathway is essential for Synechocystis; the exact opposite of the situation in Synechococcus. The most apparent difference between those two species is cell shape (coccoid vs. rod-shaped), consequently the different MinC-driven modes of FtsZ antagonism could be of different importance for different cyanobacterial cell morphotypes. It will be interesting to analyze the effect of the Min-system in Anabaena, which somewhat displays a hybrid morphotype between coccoid and rod-shaped.

Similar to MinC, Cdv3 in Synechococcus localizes to the midcell in rings [91], likely through an interaction with ZipN [92]. Overexpression of MinC and Cdv3 leads to the formation of remarkably long cell filaments, which can reach near millimeter-length for Cdv3-overexpressing strains [91,186]. As overexpression of MinC and Cdv3 does not inhibit cell growth, the increased sedimentation rates of those strains are now being exploited to optimize biomass harvesting procedures in cyanobacterial biotechnology [186]. Interestingly, low-light conditions or extended culture period (i.e., stationary phase cultures) are also associated with cell elongation in Synechococcus, leading to Min system-controlled asymmetric cell divisions [158]. The Min system enforces asymmetric division in elongated cells but ensures symmetric division in short daughter cells [187]. Notably, elongated cells produce more progeny cells than shorter ones and could act as storage units to overcome unfavorable conditions [158]. Considering all that information, it becomes apparent that cyanobacteria employ numerous mechanisms to regulate faithful cell division and utilize systems previously described to be restricted to either Gram-positive or Gram-negative bacteria. Finally, bearing in mind that many more cyanobacterial morphotypes have not yet been studied, it is conceivable that other, cyanobacterial-specific mechanisms to control cell division are yet to be discovered. Moreover, although a multitude of interactions have been identified among cell division/growth-related proteins, many other interactions are likely yet to be identified, making room to further explore the cyanobacterial cell division processes.

\section{Coiled-Coil-Rich Proteins in Cyanobacteria}

Despite relatively poor sequence conservation [188], eukaryotic intermediate filament (IF) proteins, the third major class of eukaryotic cytoskeletal proteins [2], reveal a robust tripartite building plan. IF proteins consist of highly variable $\mathrm{N}$ - and C-termini that flank a central $\alpha$-helical rod-domain of conserved size (Figure 4). The rod domain consists of different coil segments that mediate the assembly into the characteristic coiled-coil (CC) structures with other IF proteins through lateral and longitudinal association, ultimately forming long IFs with a diameter of $11 \mathrm{~nm}$ (reviewed by [189]). About two decades ago, a functional involvement of an IF-like bacterial coiled-coil-rich protein (CCRP) in cell shape was described in the curved Gram-negative bacterium C. crescentus [9]. Although Crescentin is generally considered to be the first discovered bacterial IF-like cytoskeletal protein $[190,191]$, the TlpA protein from Salmonella enterica was previously described as a bacterial CCRP with IF-like functions [192]. Nonetheless, Crescentin remains the best studied bacterial IF-like protein and has been shown to be essential for the typical crescent-like shape of $C$. crescentus. It aligns at the inner cell curvature [9], possibly mechanically controlling PG biosynthesis through a functional and potentially direct association with the MreB cytoskeleton [190]. Crescentin, reminiscent of eukaryotic IF proteins, forms filaments in vitro with a width of approximately $10 \mathrm{~nm}$ [9]. Although revealing compelling structural and domain similarities to eukaryotic IF proteins (Figure 4), given its restricted distribution to only one identified organism, Crescentin is considered to be likely no direct homologue of eukaryotic IF proteins but could rather be acquired by C. crescentus by horizontal gene transfer or as a result of convergent evolution [193-195]. The convergent evolutionary theory is supported by the ongoing discoveries of unrelated but structurally similar bacterial CCRPs that reveal IF-like characteristics. These proteins were shown to be involved in numerous different cellular functions, including cell shape (RsmP; [196]), cellular rigidity and polar PG biosynthesis (FilP, Scy and DivIVA; [197-199]), 
chemotaxis (Scc; [200]), gliding motility (AglZ; [201]), swimming motility and cell shape (Helicobacter pylori Ccrps; [78,202]), reminiscent of their eukaryotic counterparts (reviewed for example by [3,203]).

Given their seemingly ubiquitous involvement in cell shape, we recently searched for cyanobacterial CCRPs [204] that could be functionally involved in the manifestation of the enormous morphological diversity in the Cyanobacteria phylum [19]. In this study, we found that CCRPs are more prevalent in multicellular filamentous cyanobacteria compared to unicellular species. A specific reduction in CCRP proportion was identified in the genomes of the marine Picocyanobacteria, which could coincide with their reduced genome sizes [205]. The intriguing observation of higher CCRP counts in more complex cyanobacteria could indicate that CCRPs, at least in part, are important for the establishment of sophisticated morphological features in cyanobacteria. In fact, several septal junction-associated proteins, which are essential for the multicellular phenotype in Anabaena, contain CC domains [28,172]. Using a streamlined approach to readily test several candidate CCRPs with a newly developed in vitro polymerization assay allowed us to detect four novel filament-forming CCRPs in cyanobacteria. In Synechocystis, $\operatorname{Slr} 1301$ (termed $\mathrm{HmpF}_{\mathrm{Syn}}$ ) is a homologous protein to HmpF from Nostoc punctiforme [206], which, similar to its homolog, was found to be involved in Synechocystis twitching motility (as also previously identified by [207]), possibly through its interaction with the pilus ATPase PilB [204]. Despite its high CC content, $\mathrm{HmpF}_{\text {Syn }}$ did not assemble into IF-like polymers in vitro and in vivo, highlighting that the pure presence of many CC domains is not sufficient to predict IF-like properties. Another Synechocystis CCRP, Slr7083 is encoded on a plasmid (the large toxin-antitoxin plasmid pSYSA) similar to TlpA from Salmonella enterica [192]. In contrast to $\mathrm{HmpF}_{\text {Syn }}$ Slr7083 assembles into a honeycomb-like web of protein filaments in vitro and localizes circumferentially to the cell envelope. Slr7083 also affected the cellular motility of Synechocystis (although to a lesser extent) and as it directly interacted with $\mathrm{HmpF}_{\mathrm{Syn}}$, both CCRPs could be involved in cellular motility [204], reminiscent of the $H$. pylori CCRPs that regulate swimming motility [202] and AglZ, which is involved in gliding motility [201]. We also showed that a protein specific to multicellular cyanobacteria, Fm7001, polymerizes into extremely stable filamentous sheets at $4.5 \mathrm{M}$ urea, a concentration where the eukaryotic IF protein vimentin only exist as tetramers [208]. This incredibly strong self-association capacity could function in the manifestation and stabilization of the F. muscicola trichome phenotype [204]. Interestingly, we also showed for the first time that a bacterial tetratricopeptide repeat (TPR) protein, All4981 from Anabaena, assembles into filamentous structures in vivo and in vitro, while interacting with a number of S-layer proteins. Notably, no S-layer has been detected in Anabaena [209], and a deletion of all4981 could not be obtained, hampering a functional dissection of All4981. In our study [204], we further found two Synechococcus CCRPs of which Synpcc7942_1139 ( $\left.\mathrm{HmpF}_{\text {Syc }}\right)$, a Synechococcus homolog to $\mathrm{HmpF}$, is essential and has a severe impact on colony morphology, a novel trait of prokaryotic CCRPs. This essential property is in contrast to the non-essentiality of $\mathrm{HmpF}$ and $\mathrm{HmpF}_{\text {Syn }}$, suggesting specific functional adaptations to Synechococcus. Both mutants of $h m p F_{S y c}$ and synpcc7942_2039 (hereafter syc2039) resulted in an elongated cell morphotype, reminiscent of other cell division genes previously identified in Synechococcus, including $f t s Z, f t n 2(z i p N), f \operatorname{tn} 6(z i p S), c i k A, c d v 1$, $c d v 2, c d v 3, \operatorname{clpX}$, and $\operatorname{minE}[86,91,210]$, indicating an impact of $\mathrm{HmpF}_{\mathrm{Syc}}$ and Syc2039 on cell division. However, the cell elongation effect was not as severe as in the zipN and zipS mutants [86]. While the localization of $\mathrm{HmpF}_{\text {Syc }}$ was largely inconclusive, Syc2039-GFP formed spindle-like filamentous structures within several cyanobacterial strains and in E. coli, suggesting a strong self-sufficient assembly property. Nonetheless, in vitro Syc2039 filaments were not observed. Instead, Syc2039 seemed to rather be involved in DNA segregation as cells lacking syc2039 revealed an altered DNA distribution within the cell, reminiscent of Synechococcus cells treated with thiabendazole, a tubulin assembly inhibitor [145]. Although membrane association of bacterial CCRPs was described before (reviewed by [190]), no bacterial CCRP containing a transmembrane domain has been identified so far (reviewed by [12]). Consequently, the existing N-terminal TDM in Syc2039 further suggests that Syc2039 does not itself form filaments but rather associates with another filamentous system in bacteria [204]. Collectively, the myriad of different functional properties of cyanobacterial CCRPs, 
including cell and colony shape, cell division, motility, DNA segregation, and trichome integrity provide an initial foundation for future studies on the impact of CCRPs on the morphological and functional diversification in cyanobacteria. The employed in vitro polymerization assay using an unspecific NHS-fluorescein dye proved to be a valuable tool to conveniently detect polymerizing proteins in vitro (for a list of polymerizing cyanobacterial proteins see Figure 4) and could facilitate the identification of other filamentous proteins. We are currently working on the additional characterization of several Anabaena CCRPs and initial results indicate that some of those CCRPs, including ZicK and ZacK, could be involved in the stabilization of the linear trichome phenotype in Anabaena, extending the known impact of CCRPs from cell shape to trichome shape [211]. Noteworthy, ZicK and ZacK were also observed to be strictly interdependent to form heteropolymers in vitro and in vivo, describing a novel trait of bacterial CCRPs [211].

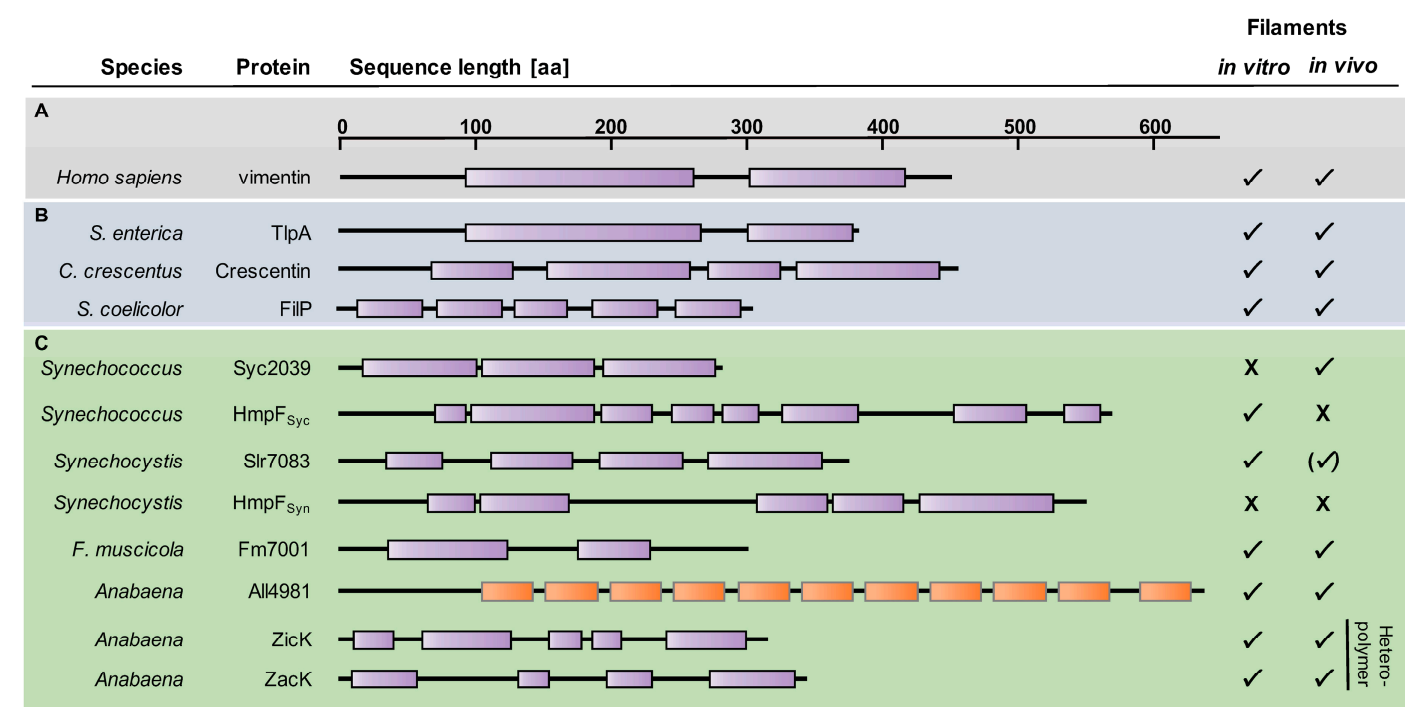

Figure 4. Bacterial coiled-coil-rich proteins. Depiction of coiled-coil-rich-regions (purple rectangles) in (A) the human vimentin, (B) previously described bacterial CCRPs, and (C) recently identified cyanobacterial CCRPs. Coiled-coil-rich regions were predicted using the COILS algorithm [212] or were obtained from $[9,197,204,211]$. Orange rectangles indicate TPR repeats that are also identified as coiled-coils by the COILS algorithm. Vimentin [188]; TlpA [192]; Crescentin [9]; FilP [197], Syc2039, $\mathrm{HmpF}_{\text {Syc }}$, Slr7083, HmpF $F_{\text {Syn }}$, Fm7001, All4981 [204]; ZicK, ZacK [211].

\section{Undescribed Filamentous Systems in Cyanobacteria}

Despite our analysis at the gene level, several conventional electron microscopy studies reported tubular, possibly cytoskeletal features in diverse cyanobacteria; however, they always lacked a clear identification of their protein composition. These observations can be divided into two subclasses: Microtubule-like structures (10-22 $\mathrm{nm}$ in diameter, length up to more than $1 \mu \mathrm{m}$ ) or thinner (3-8 $\mathrm{nm}$ in diameter) and less rigid microfilaments. Already in the late 1960s, a study observed microtubule-resembling, $300 \mathrm{~nm}$ long structures with a diameter of $15 \mathrm{~nm}$ in an uncharacterized Synechococcus strain [213]. Thin sections of Nostoc strains revealed an even more intricate arrangement of tubules, consisting of an amorphous, $\sim 1 \mu \mathrm{m}$ long base plate parallel to the septum and numerous microtubule-like filaments perpendicular to it, protruding towards the cell center [214]. A similar complex could be visualized in Anabaena ([215] and reviewed in [216]); however, the described architecture shows strong similarities to phycobilisome arrays bound to thylakoid membranes, which were recently resolved in a native state in Synechocystis with cryo-electron tomography (cryoET) [217]. In Anabaena, it was further speculated that microtubular filaments could be important for the positioning of carboxysomes [215], whereas, the reported striated microtubules and sleeve bodies (Figure 5A) more resemble a membranous compartment or vesicles if re-analyzed with today's 
knowledge and to a lesser extent cytoskeletal features [215]. In contrast, the finding of tubular structures bound to the cytoplasmic membrane in two Nostoc strains is even more remarkable nowadays [218], as they show striking similarities to the phage tail-like apparatus of the bacterial type VI secretion system, which was structurally discovered more than 30 years later and has not yet been identified in cyanobacteria [219]. The second prominent observations, which were termed microfilaments, could be visualized only in Anabaena [215] and in Cyanothece [220]. These finer filaments were observed in all areas of the cytoplasm and similar findings were recently made in our lab (unpublished), after artefact free-thinning of frozen-hydrated Anabaena cells with cryo-focused ion beam (FIB) milling [221] and subsequent cryoET. Multiple $5 \mathrm{~nm}$ wide and $>500 \mathrm{~nm}$ long filaments bundled up in the cytoplasm and a repetitive subunit every $5.5 \mathrm{~nm}$ was discernible (Figure 5B). No discrete anchoring towards a membrane was detectable, although one end often co-localized with a thylakoid membrane stack. In cross-sections, the filaments revealed a tight packing with a center to center spacing of $11 \mathrm{~nm}$ (Figure 5 C). We could observe these filaments in $\sim 2 \%$ of our tomograms ( $n>500$ tomograms), which does not reasonably allow the suggestion of a function. Nevertheless, these data show that the cyanobacterial cytoskeleton is not yet fully understood and an integrative, multi-scale approach, from molecular biology to near-native imaging techniques like cryoET, is crucial to elucidate its diverse functions.
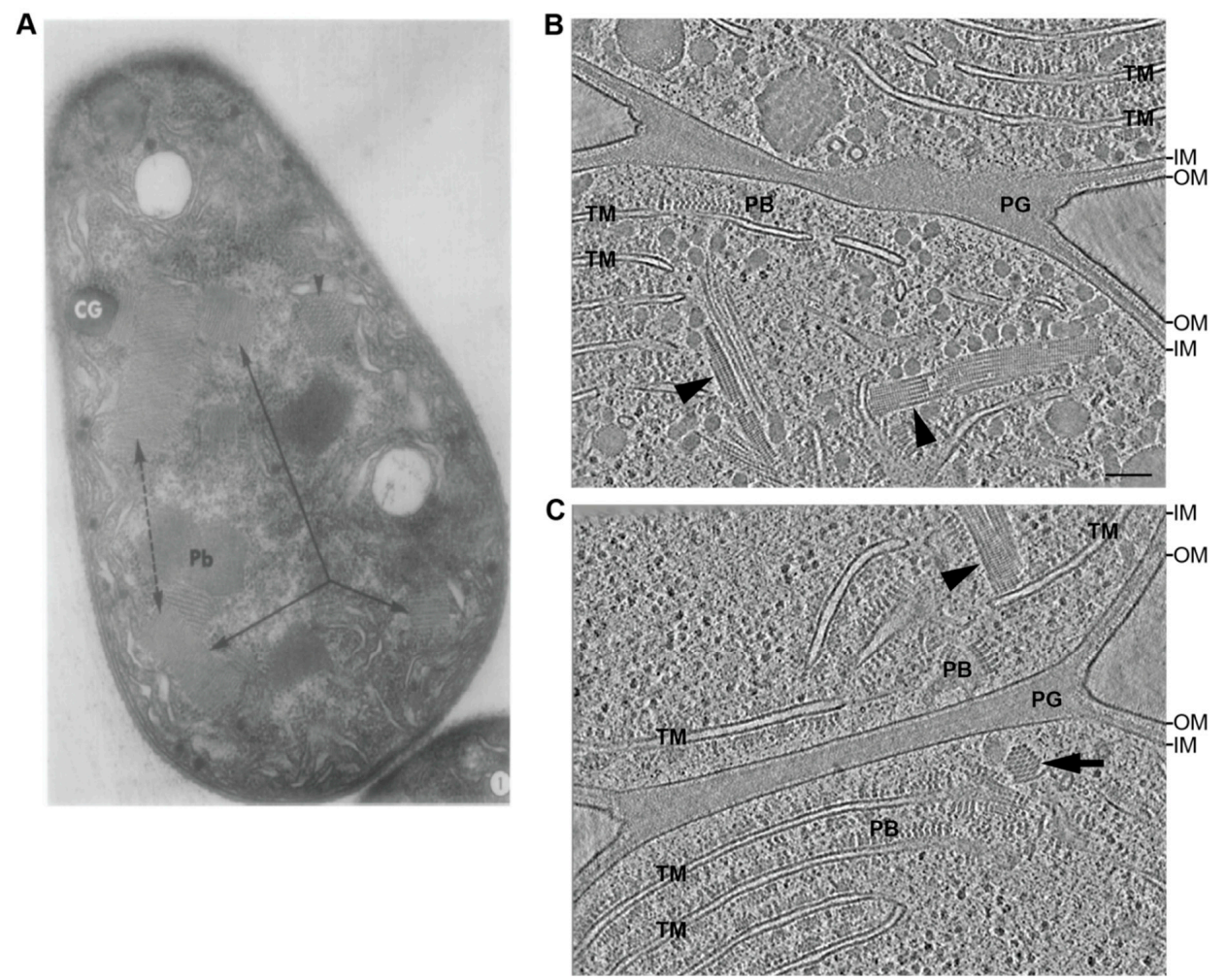

Figure 5. Electron micrographs of Anabaena. (A) Thin section of Anabaena minutissima showing striated microtubules (indicated by arrows). $\mathrm{Pb}$, polyhedral bodies; CG, cyanophycin granule. (B,C) Cryo-electron tomograms of Anabaena showing uncharacterized intracellular filaments. (B) $5 \mathrm{~nm}$ wide filaments, with repetitive units every $5.5 \mathrm{~nm}$, bundled together in the cytoplasm (arrowheads) and spanning parts of the cell. (C) Cross-section of these bundles revealed a tight packing with $11 \mathrm{~nm}$ spacing between filament centres (arrow). IM, inner membrane; OM, outer membrane; PB, phycobilisomes; PG, peptidoglycan; TM, thylakoid membrane. Bars, $100 \mathrm{~nm}$. Shown are $13.5 \mathrm{~nm}$ thick slices. Figure 5A is reprinted from "The fine structure of striated microtubules and sleeve bodies in several species of Anabaena" [215], vol. 57, 1976, by Thomas E. Jensen and Robert P. Ayala with permission from Elsevier. 


\section{Conclusions and Future Perspectives}

Recent scientific advances in the field of cyanobacterial research have started to unravel the mysteries and the evolution of cyanobacterial multicellularity, the cell-cell communication in multicellular cyanobacteria as well as cyanobacterial motility and provided growing insight into the molecular mechanisms that govern cell division and growth. This led to the insight that cyanobacteria are not just a mixture of Gram-positive and Gram-negative bacteria based on their cell wall characteristics but also because they harbor cell division genes specific to both Gram types and additionally possess cyanobacteria-specific cell division genes. Especially in multicellular cyanobacteria, a direct interplay between cell division processes and the establishment of cell-cell communication and ultimately multicellularity seems to exist. In the future, it will be of interest to analyze whether the cell shape-determining and MreB-driven elongasome is also linked to the incomplete cell separation process and intercellular communication in multicellular cyanobacteria. However, even apart from multicellular cyanobacteria and as a result of their mixed Gram phenotypes, it is intriguing to speculate that unicellular cyanobacteria have also evolved cell elongation processes and thus, elongasome functions in an alternative way to the well described model systems such as E. coli and B. subtilis. Nonetheless, given that several cell division processes appear to be cell shape-specific rather than phylum-specific, general statements about the functional properties of single proteins will likely remain restricted to the species or subsection level. The recent identification of cyanobacterial CCRPs with the property to form filament-like structures and their seemingly diverse cellular roles suggests that, at least in part, these proteins, like in other bacteria, could contribute to the special phenotype of cyanobacteria. The characterization of cell growth, cell division, and cytoskeletal processes in cyanobacteria has just begun and will likely provide us with unique insights into those fascinating bacteria. Technical advances like artefact-free sample thinning with cryo-FIB milling combined with correlative cryo-light microscopy/electron tomography will further allow in vivo visualization of these cytoskeletal features in a native state. Given their enormous ecological importance as primary inventors of oxygenic photosynthesis and their increasing importance due to the emerging climate change, cyanobacteria will likely receive more and more attention in the future that will also allow us to better understand their molecular circuits and consequently their unique adaptation strategies to the vast habitats that cyanobacteria populate.

Author Contributions: Conceptualization, B.L.S. and K.S.; Writing-Original Draft Preparation, B.L.S., D.J.N., G.L.W., M.P. and K.S.; Writing-Review \& Editing, B.L.S., D.J.N., G.L.W., M.P. and K.S. All authors have read and agreed to the published version of the manuscript.

Funding: This research was funded by B.L.S. was supported by a "Maximizing Investigators' Research Award" (MIRA; No. R35GM136247) awarded to Ann Hochschild (Harvard Medical School, Boston, USA). D.J.N. is supported by the German Research Foundation (DFG; Deutsche Forschungsgemeinschaf) for an Emmy Noether project. K.S. was supported by the DFG (No. STU513/2-1) and ANID, ANID Fondecyt (No. 11170842). The APC was funded by the funding agencies of K.S., G.L.W. was supported by a Boehringer Ingelheim Fonds PhD fellowship. M.P. was supported by the Swiss National Science Foundation (\#31003A_179255), the European Research Council (\#679209) and the NOMIS foundation.

Conflicts of Interest: The authors declare no conflict of interest. The funders had no role in the design of the study; in the collection, analyses, or interpretation of data; in the writing of the manuscript, or in the decision to publish the results.

Data Availability: No new data were created or analyzed in this study. Data sharing is not applicable to this article.

\section{References}

1. Moseley, J.B. An expanded view of the eukaryotic cytoskeleton. Mol. Biol. Cell 2013, 24, 1615-1618. [CrossRef] [PubMed]

2. Alberts, B.; Johnson, A.; Lewis, J.; Morgan, D.; Raff, M.; Roberts, K.; Walter, P. Molecular Biology of the Cell, 6th ed.; Garland Science: New York, NY, USA, 2014.

3. Huber, F.; Boire, A.; López, M.P.; Koenderink, G.H. Cytoskeletal crosstalk: When three different personalities team up. Curr. Opin. Cell Biol. 2015, 32, 39-47. [CrossRef] 
4. Bi, E.; Lutkenhaus, J. FtsZ ring structure associated with division in Escherichia coli. Nature 1991, 354, 161-164. [CrossRef] [PubMed]

5. De Boer, P.; Crossley, R.; Rothfield, L. The essential bacterial cell-division protein FtsZ is a GTPase. Nature 1992, 359, 254-256. [CrossRef] [PubMed]

6. Löwe, J.; Amos, L.A. Crystal structure of the bacterial cell division protein FtsZ. Nature 1998, 391, $203-206$. [CrossRef] [PubMed]

7. Bork, P.; Sander, C.; Valencia, A. An ATPase domain common to prokaryotic cell cycle proteins, sugar kinases, actin, and hsp70 heat shock proteins. Proc. Natl. Acad. Sci. USA 1992, 89, 7290-7294. [CrossRef] [PubMed]

8. Van den Ent, F.; Amos, L.A.; Löwe, J. Prokrayotic origin of the actin cytoskeleton. Nature 2001, 413, $39-44$. [CrossRef]

9. Ausmees, N.; Kuhn, J.R.; Jacobs-Wagner, C. The bacterial cytoskeleton: An intermediate filament-like function in cell shape. Cell 2003, 115, 705-713. [CrossRef]

10. Kühn, J.; Briegel, A.; Mörschel, E.; Kahnt, J.; Leser, K.; Wick, S.; Jensen, G.J.; Thanbichler, M. Bactofilins, a ubiquitous class of cytoskeletal proteins mediating polar localization of a cell wall synthase in Caulobacter crescentus. EMBO J. 2010, 29, 327-339. [CrossRef]

11. Lin, L.; Thanbichler, M. Nucleotide-independent cytoskeletal scaffolds in bacteria. Cytoskeleton 2013, 70, 409-423. [CrossRef]

12. Wagstaff, J.; Löwe, J. Prokaryotic cytoskeletons: Protein filaments organizing small cells. Nat. Rev. Microbiol. 2018, 16, 187-201. [CrossRef] [PubMed]

13. Videau, P.; Rivers, O.S.; Ushijima, B.; Oshiro, R.T.; Kim, M.J.; Philmus, B.; Cozy, L.M. Mutation of the murC and murB genes impairs heterocyst differentiation in Anabaena sp. strain PCC 7120. J. Bacteriol. 2016, 198, 1-12. [CrossRef] [PubMed]

14. Hoiczyk, E.; Baumeister, W. Envelope structure of four gliding filamentous cyanobacteria. J. Bacteriol. 1995, 177, 2387-2395. [CrossRef] [PubMed]

15. Gumbart, J.C.; Beeby, M.; Jensen, G.J.; Roux, B. Escherichia coli peptidoglycan structure and mechanics as predicted by atomic-scale simulations. PLoS Comput. Biol. 2014, 10, e1003475. [CrossRef]

16. Hoiczyk, E.; Hansel, A. Cyanobacterial cell walls: News from an unusual prokaryotic envelope. J. Bacteriol. 2000, 182, 1191-1199. [CrossRef]

17. Cassier-Chauvat, C.; Chauvat, F. Cell division in cyanobacteria. In The Cell Biology of Cyanobacteria; Flores, E., Herrero, A., Eds.; Caister Academic Press: Rover, UK, 2014.

18. Schirrmeister, B.E.; Antonelli, A.; Bagheri, H.C. The origin of multicellularity in cyanobacteria. BMC Evol. Biol. 2011, 11, 45. [CrossRef]

19. Rippka, R.; Stanier, R.Y.; Deruelles, J.; Herdman, M.; Waterbury, J.B. Generic assignments, strain histories and properties of pure cultures of cyanobacteria. Microbiology 1979, 111, 1-61. [CrossRef]

20. Dagan, T.; Roettger, M.; Stucken, K.; Landan, G.; Koch, R.; Major, P.; Gould, S.B.; Goremykin, V.V.; Rippka, R.; De Marsac, N.T.; et al. Genomes of stigonematalean cyanobacteria (subsection V) and the evolution of oxygenic photosynthesis from prokaryotes to plastids. Genome Biol. Evol. 2013, 5, 31-44. [CrossRef]

21. Shih, P.M.; Wu, D.; Latifi, A.; Axen, S.D.; Fewer, D.P.; Talla, E.; Calteau, A.; Cai, F.; Tandeau de Marsac, N.; Rippka, R.; et al. Improving the coverage of the cyanobacterial phylum using diversity-driven genome sequencing. Proc. Natl. Acad. Sci. USA 2013, 110, 1053-1058. [CrossRef]

22. Koch, R.; Kupczok, A.; Stucken, K.; Ilhan, J.; Hammerschmidt, K.; Dagan, T. Plasticity first: Molecular signatures of a complex morphological trait in filamentous cyanobacteria. BMC Evol. Biol. 2017, 17, 1-11. [CrossRef]

23. Weiss, G.L.; Kieninger, A.-K.; Maldener, I.; Forchhammer, K.; Pilhofer, M. Structure and function of a bacterial gap junction analog. Cell 2019, 178, 374-384.e15. [CrossRef] [PubMed]

24. Nürnberg, D.J.; Mariscal, V.; Bornikoel, J.; Nieves-Morión, M.; Krauß, N.; Herrero, A.; Maldener, I.; Flores, E.; Mullineaux, C.W. Intercellular diffusion of a fluorescent sucrose analog via the septal junctions in a filamentous cyanobacterium. MBio 2015, 6, 1-12. [CrossRef] [PubMed]

25. Kieninger, A.K.; Forchhammer, K.; Maldener, I. A nanopore array in the septal peptidoglycan hosts gated septal junctions for cell-cell communication in multicellular cyanobacteria. Int. J. Med. Microbiol. 2019, 309, 151303. [CrossRef] [PubMed] 
26. Lehner, J.; Zhang, Y.; Berendt, S.; Rasse, T.M.; Forchhammer, K.; Maldener, I. The morphogene AmiC2 is pivotal for multicellular development in the cyanobacterium Nostoc punctiforme. Mol. Microbiol. 2011, 79, 1655-1669. [CrossRef] [PubMed]

27. Nayar, A.S.; Yamaura, H.; Rajagopalan, R.; Risser, D.D.; Callahan, S.M. FraG is necessary for filament integrity and heterocyst maturation in the cyanobacterium Anabaena sp. strain PCC 7120. Microbiology 2007, 153, 601-607. [CrossRef] [PubMed]

28. Herrero, A.; Stavans, J.; Flores, E. The multicellular nature of filamentous heterocyst-forming cyanobacteria. FEMS Microbiol. Rev. 2016, 40, 831-854. [CrossRef] [PubMed]

29. Flores, E.; Nieves-Morión, M.; Mullineaux, C. Cyanobacterial septal junctions: Properties and regulation. Life 2018, 9, 1. [CrossRef]

30. Flores, E.; Herrero, A. Compartmentalized function through cell differentiation in filamentous cyanobacteria. Nat. Rev. Microbiol. 2010, 8, 39-50. [CrossRef]

31. Gaysina, L.A.; Saraf, A.; Singh, P. Cyanobacteria in diverse habitats. In Cyanobacteria-From Basic Science to Applications; Mishra, A.K., Tiwari, D.N., Rai, A.N.B.T.-C., Eds.; Academic Press: Cambridge, MA, USA, 2019; pp. 1-28.

32. Pospíšil, P. Production of reactive oxygen species by photosystem II as a response to light and temperature stress. Front. Plant Sci. 2016, 7, 1950. [CrossRef]

33. Larkum, A.W.D.; Ritchie, R.J.; Raven, J.A. Living off the sun: Chlorophylls, bacteriochlorophylls and rhodopsins. Photosynthetica 2018, 56, 11-43. [CrossRef]

34. Wiltbank, L.B.; Kehoe, D.M. Diverse light responses of cyanobacteria mediated by phytochrome superfamily photoreceptors. Nat. Rev. Microbiol. 2019, 17, 37-50. [CrossRef] [PubMed]

35. Yerrapragada, S.; Shukla, A.; Hallsworth-Pepin, K.; Choi, K.; Wollam, A.; Clifton, S.; Qin, X.; Muzny, D.; Raghuraman, S.; Ashki, H.; et al. Extreme sensory complexity encoded in the 10-megabase draft genome Sequence of the chromatically acclimating cyanobacterium tolypothrix sp. PCC 7601. Genome Announc. 2015, 3, e00355-15. [CrossRef] [PubMed]

36. Bennett, A.; Bogorad, L. Complementary chromatic adaptation in a filamentous blue-green alga. J. Cell Biol. 1973, 58, 419. [CrossRef] [PubMed]

37. Sanfilippo, J.E.; Garczarek, L.; Partensky, F.; Kehoe, D.M. Chromatic acclimation in cyanobacteria: A diverse and widespread process for optimizing photosynthesis. Annu. Rev. Microbiol. 2019, 73, 407-433. [CrossRef] [PubMed]

38. Kehoe, D.M.; Grossman, A.R. Similarity of a chromatic adaptation sensor to phytochrome and ethylene receptors. Science 1996, 273, 1409-1412. [CrossRef]

39. Terauchi, K.; Montgomery, B.L.; Grossman, A.R.; Lagarias, J.C.; Kehoe, D.M. RcaE is a complementary chromatic adaptation photoreceptor required for green and red light responsiveness. Mol. Microbiol. 2004, 51,567-577. [CrossRef]

40. Bordowitz, J.R.; Montgomery, B.L. Photoregulation of cellular morphology during complementary chromatic adaptation requires sensor-kinase-class protein RcaE in Fremyella diplosiphon. J. Bacteriol. 2008, 190, 4069-4074. [CrossRef]

41. Singh, S.P.; Montgomery, B.L. Morphogenes bolA and mreB mediate the photoregulation of cellular morphology during complementary chromatic acclimation in Fremyella diplosiphon. Mol. Microbiol. 2014, 93, 167-182. [CrossRef]

42. Wilde, A.; Mullineaux, C.W. Light-controlled motility in prokaryotes and the problem of directional light perception. FEMS Microbiol. Rev. 2017, 41, 900-922. [CrossRef]

43. Robinson, B.L.; Miller, J.H. Photomorphogenesis in the blue-green alga Nostoc commune 584. Physiol. Plant. 1970, 23, 461-472. [CrossRef]

44. Meeks, J.C.; Campbell, E.L.; Summers, M.L.; Wong, F.C. Cellular differentiation in the cyanobacterium Nostoc punctiforme. Arch. Microbiol. 2002, 178, 395-403. [CrossRef]

45. Damerval, T.; Guglielmi, G.; Houmard, J.; De Marsac, N.T. Hormogonium differentiation in the cyanobacterium Calothrix: A photoregulated developmental process. Plant Cell 1991, 3, 191-201. [CrossRef] [PubMed]

46. Zepu, Z.; Yuhuan, W.; Jie, X.; Lijie, F.; Dingji, S. Differentiation of hormogonia and photosynthetic characterization of Nostoc flagelliforme. Acta Bot. Sin. 2000, 42, 570-575. 
47. Campbell, D.; Houmard, J.; De Marsac, N.T. Electron transport regulates cellular differentiation in the filamentous cyanobacterium Calothrix. Plant Cell 1993, 5, 451-463. [CrossRef] [PubMed]

48. Khamar, H.J.; Breathwaite, E.K.; Prasse, C.E.; Fraley, E.R.; Secor, C.R.; Chibane, F.L.; Elhai, J.; Chiu, W.-L. Multiple roles of soluble sugars in the establishment of Gunnera-Nostoc endosymbiosis. Plant Physiol. 2010, 154, 1381-1389. [CrossRef] [PubMed]

49. Meeks, J.C.; Elhai, J. Regulation of cellular differentiation in filamentous cyanobacteria in free-living and plant-associated symbiotic growth states. Microbiol. Mol. Biol. Rev. 2002, 66, 94-121. [CrossRef] [PubMed]

50. Liaimer, A.; Helfrich, E.J.N.; Hinrichs, K.; Guljamow, A.; Ishida, K.; Hertweck, C.; Dittmann, E. Nostopeptolide plays a governing role during cellular differentiation of the symbiotic cyanobacterium Nostoc punctiforme. Proc. Natl. Acad. Sci. USA 2015, 112, 1862-1867. [CrossRef] [PubMed]

51. Hashidoko, Y.; Nishizuka, H.; Tanaka, M.; Murata, K.; Murai, Y.; Hashimoto, M. Isolation and characterization of 1-palmitoyl-2-linoleoyl-sn-glycerol as a hormogonium-inducing factor (HIF) from the coralloid roots of Cycas revoluta (Cycadaceae). Sci. Rep. 2019, 9, 1-12. [CrossRef]

52. Nürnberg, D.J.; Mariscal, V.; Parker, J.; Mastroianni, G.; Flores, E.; Mullineaux, C.W. Branching and intercellular communication in the Section V cyanobacterium Mastigocladus laminosus, a complex multicellular prokaryote. Mol. Microbiol. 2014, 91, 935-949. [CrossRef]

53. Campbell, E.L.; Meeks, J.C. Characteristics of hormogonia formation by symbiotic Nostoc spp. in response to the presence of anthoceros punctatus or its extracellular products. Appl. Environ. Microbiol. 1989, 55, 125-131. [CrossRef]

54. Adams, D.G.; Bergman, B.; Nierzwicki-Bauer, S.A.; Duggan, P.S.; Rai, A.N.; Schüßler, A. Cyanobacterial-plant symbioses. In The Prokaryotes: Prokaryotic Biology and Symbiotic Associations; Rosenberg, E., DeLong, E.F., Lory, S., Stackebrandt, E., Thompson, F., Eds.; Springer: Berlin/Heidelberg, Germany, 2013; pp. 359-400.

55. Decelle, J.; Colin, S.; Foster, R.A. Photosymbiosis in marine planktonic protists. In Marine Protists: Diversity and Dynamics; Ohtsuka, S., Suzaki, T., Horiguchi, T., Suzuki, N., Not, F., Eds.; Springer: Tokyo, Japan, 2015; pp. 465-500.

56. Peters, G.A.; Perkins, S.K. The Azolla-Anabaena symbiosis: Endophyte continuity in the Azolla life-cycle is facilitated by epidermal trichomes. New Phytol. 1993, 123, 65-75. [CrossRef]

57. Caputo, A.; Nylander, J.A.A.; Foster, R.A. The genetic diversity and evolution of diatom-diazotroph associations highlights traits favoring symbiont integration. FEMS Microbiol. Lett. 2019, 366, fny297. [CrossRef] [PubMed]

58. Velázquez-Suárez, C.; Luque, I.; Herrero, A. The inorganic nutrient regime and the mre genes regulate cell and filament size and morphology in the phototrophic multicellular bacterium Anabaena. MSphere 2020, 5, e00747-20. [CrossRef] [PubMed]

59. Singh, S.P.; Montgomery, B.L. Determining cell shape: Adaptive regulation of cyanobacterial cellular differentiation and morphology. Trends Microbiol. 2011, 19, 278-285. [CrossRef] [PubMed]

60. Claessen, D.; Rozen, D.E.; Kuipers, O.P.; Søgaard-Andersen, L.; Van Wezel, G.P. Bacterial solutions to multicellularity: A tale of biofilms, filaments and fruiting bodies. Nat. Rev. Microbiol. 2014, 12, 115-124. [CrossRef] [PubMed]

61. Zhu, Z.; Piao, S.; Myneni, R.B.; Huang, M.; Zeng, Z.; Canadell, J.G.; Ciais, P.; Sitch, S.; Friedlingstein, P.; Arneth, A.; et al. Greening of the Earth and its drivers. Nat. Clim. Chang. 2016, 6, 791-795. [CrossRef]

62. Caccamo, P.D.; Brun, Y.V. The molecular basis of noncanonical bacterial morphology. Trends Microbiol. 2018, 26, 191-208. [CrossRef]

63. Lange, R.; Hengge-Aronis, R. Growth phase-regulated expression of bolA and morphology of stationary-phase Escherichia coli cells are controlled by the novel sigma factor $\sigma(\mathrm{S})$. J. Bacteriol. 1991, 173, 4474-4481. [CrossRef]

64. Young, K.D. The selective value of bacterial shape. Microbiol. Mol. Biol. Rev. 2006, 70, 660-703. [CrossRef]

65. Typas, A.; Banzhaf, M.; Gross, C.A.; Vollmer, W. From the regulation of peptidoglycan synthesis to bacterial growth and morphology. Nat. Rev. Microbiol. 2012, 10, 123. [CrossRef]

66. Egan, A.J.F.; Errington, J.; Vollmer, W. Regulation of peptidoglycan synthesis and remodelling. Nat. Rev. Microbiol. 2020, 18, 446-460. [CrossRef] [PubMed]

67. Pinho, M.G.; Kjos, M.; Veening, J.W. How to get (a)round: Mechanisms controlling growth and division of coccoid bacteria. Nat. Rev. Microbiol. 2013, 11, 601-614. [CrossRef] [PubMed] 
68. Errington, J.; Wu, L.J. Cell cycle machinery in bacillus subtilis. In Prokaryotic Cytoskeletons: Filamentous Protein Polymers Active in the Cytoplasm of Bacterial and Archaeal Cells; Löwe, J., Amos, L.A., Eds.; Springer: Berlin/Heidelberg, Germany, 2017; pp. 67-101.

69. Den Blaauwen, T.; De Pedro, M.A.; Nguyen-Disteche, M.; Ayala, J.A. Morphogenesis of rod-shaped sacculi. FEMS Microbiol. Rev. 2008, 32, 321-344. [CrossRef]

70. Jones, L.J.F.; Carballido-López, R.; Errington, J. Control of cell shape in bacteria: Helical, actin-like filaments in Bacillus subtilis. Cell 2001, 104, 913-922. [CrossRef]

71. Kruse, T.; Bork-Jensen, J.; Gerdes, K. The morphogenetic MreBCD proteins of Escherichia coli form an essential membrane-bound complex. Mol. Microbiol. 2005, 55, 78-89. [CrossRef]

72. Domínguez-Escobar, J.; Chastanet, A.; Crevenna, A.H.; Fromion, V.; Wedlich-Söldner, R.; Carballido-López, R. Processive movement of MreB-associated cell wall biosynthetic complexes in bacteria. Science 2011, 333, 225-228. [CrossRef]

73. Garner, E.C.; Bernard, R.; Wang, W.; Zhuang, X.; Rudner, D.Z.; Mitchison, T. Circumferential motions of the cell wall synthesis machinery drive cytoskeletal dynamics in B. subtilis. Science 2011, 333, $222-225$. [CrossRef]

74. Van Teeffelen, S.; Wang, S.; Furchtgott, L.; Huang, K.C.; Wingreen, N.S.; Shaevitz, J.W.; Gitai, Z. The bacterial actin MreB rotates, and rotation depends on cell-wall assembly. Proc. Natl. Acad. Sci. USA 2011, 108, 15822-7. [CrossRef]

75. Siefert, J.L.; Fox, G.E. Phylogenetic mapping of bacterial morphology. Microbiology 1998, 144, $2803-2808$. [CrossRef]

76. Yulo, P.R.J.; Hendrickson, H.L. The evolution of spherical cell shape; progress and perspective. Biochem. Soc. Trans. 2019, 47, 1621-1634. [CrossRef]

77. Springstein, B.L.; Weissenbach, J.; Koch, R.; Stücker, F.; Stucken, K. The role of the cytoskeletal proteins MreB and FtsZ in multicellular cyanobacteria. FEBS Open Biol. 2020, 10, 2510-2531. [CrossRef] [PubMed]

78. Waidner, B.; Specht, M.; Dempwolff, F.; Haeberer, K.; Schaetzle, S.; Speth, V.; Kist, M.; Graumann, P.L. A novel system of cytoskeletal elements in the human pathogen Helicobacter pylori. PLoS Pathog. 2009, 5, e1000669. [CrossRef] [PubMed]

79. Sycuro, L.K.; Pincus, Z.; Gutierrez, K.D.; Biboy, J.; Stern, C.A.; Vollmer, W.; Salama, N.R. Peptidoglycan crosslinking relaxation promotes helicobacter pylori's helical shape and stomach colonization. Cell 2010, 141, 822-833. [CrossRef]

80. Zhi, P.W.; Zhao, Y. Morphological reversion of Spirulina (Arthrospira) platensis (Cyanophyta): From linear to helical. J. Phycol. 2005, 41, 622-628.

81. Savage, D.F.; Afonso, B.; Chen, A.H.; Silver, P.A. Spatially ordered dynamics of the bacterial carbon fixation machinery. Science 2010, 327, 1258-1261. [CrossRef] [PubMed]

82. Moore, K.A.; Tay, J.W.; Cameron, J.C. Multi-generational analysis and manipulation of chromosomes in a polyploid cyanobacterium. BioRxiv 2019, 661256. [CrossRef]

83. Watanabe, S.; Noda, A.; Ohbayashi, R.; Uchioke, K.; Kurihara, A.; Nakatake, S.; Morioka, S.; Kanesaki, Y.; Chibazakura, T.; Yoshikawa, H. ParA-like protein influences the distribution of multi-copy chromosomes in cyanobacterium Synechococcus elongatus PCC 7942. Microbiology 2018, 164, 45-56. [CrossRef] [PubMed]

84. Hu, B.; Yang, G.; Zhao, W.; Zhang, Y.; Zhao, J. MreB is important for cell shape but not for chromosome segregation of the filamentous cyanobacterium Anabaena sp. PCC 7120. Mol. Microbiol. 2007, 63, 1640-1652. [CrossRef]

85. Watanabe, S. Cyanobacterial multi-copy chromosomes and their replication. Biosci. Biotechnol. Biochem. 2020, 84, 1309-1321. [CrossRef]

86. Miyagishima, S.Y.; Wolk, P.P.; Osteryoung, K.W. Identification of cyanobacterial cell division genes by comparative and mutational analyses. Mol. Microbiol. 2005, 56, 126-143. [CrossRef]

87. Ramos-León, F.; Mariscal, V.; Frías, J.E.; Flores, E.; Herrero, A. Divisome-dependent subcellular localization of cell-cell joining protein SepJ in the filamentous cyanobacterium Anabaena. Mol. Microbiol. 2015, 96, 566-580. [CrossRef] [PubMed]

88. Mazouni, K.; Domain, F.; Cassier-Chauvat, C.; Chauvat, F. Molecular analysis of the key cytokinetic components of cyanobacteria: FtsZ, ZipN and MinCDE. Mol. Microbiol. 2004, 52, 1145-1158. [CrossRef] [PubMed] 
89. Koksharova, O.A.; Wolk, C.P. A novel gene that bears a DnaJ motif influences cyanobacterial cell division. J. Bacteriol. 2002, 184, 5524-5528. [CrossRef] [PubMed]

90. Marbouty, M.; Saguez, C.; Cassier-Chauvat, C.; Chauvat, F. Characterization of the FtsZ-interacting septal proteins SepF and Ftn6 in the spherical-celled cyanobacterium Synechocystis strain PCC 6803. J. Bacteriol. 2009, 191, 6178-6185. [CrossRef]

91. MacCready, J.S.; Schossau, J.; Osteryoung, K.W.; Ducat, D.C. Robust min-system oscillation in the presence of internal photosynthetic membranes in cyanobacteria. Mol. Microbiol. 2017, 103, 483-503. [CrossRef]

92. Marbouty, M.; Saguez, C.; Cassier-Chauvat, C.; Chauvat, F. ZipN, an FtsA-like orchestrator of divisome assembly in the model cyanobacterium Synechocystis PCC6803. Mol. Microbiol. 2009, 74, 409-420. [CrossRef]

93. Stucken, K.; Ilhan, J.; Roettger, M.; Dagan, T.; Martin, W.F. Transformation and conjugal transfer of foreign genes into the filamentous multicellular cyanobacteria (subsection V) Fischerella and Chlorogloeopsis. Curr. Microbiol. 2012, 65, 552-560. [CrossRef]

94. Liu, P.; Zheng, H.; Meng, Q.; Terahara, N.; Gu, W.; Wang, S.; Zhao, G.; Nakane, D.; Wang, W.; Miyata, M. Chemotaxis without conventional two-component system, based on cell polarity and aerobic conditions in helicity-switching swimming of Spiroplasma eriocheiris. Front. Microbiol. 2017, 8, 1-13. [CrossRef]

95. Kürner, J.; Frangakis, A.S.; Baumeister, W. Cryo-electron tomography reveals the cytoskeletal structure of Spiroplasma melliferum. Science 2005, 307, 436-438. [CrossRef]

96. Ehlers, K.; Oster, G. On the mysterious propulsion of synechococcus. PLoS ONE 2012, 7, e36081. [CrossRef]

97. Campbell, E.L.; Summers, M.L.; Christman, H.; Martin, M.E.; Meeks, J.C. Global gene expression patterns of Nostoc punctiforme in steady-state dinitrogen-grown heterocyst-containing cultures and at single time points during the differentiation of akinetes and hormogonia. J. Bacteriol. 2007, 189, 5247-5256. [CrossRef] [PubMed]

98. Campbell, E.L.; Christman, H.; Meeks, J.C. DNA microarray comparisons of plant factor- and nitrogen deprivation-induced hormogonia reveal decision-making transcriptional regulation patterns in Nostoc punctiforme. J. Bacteriol. 2008, 190, 7382LP-7391LP. [CrossRef]

99. Kabeya, Y.; Nakanishi, H.; Suzuki, K.; Ichikawa, T.; Kondou, Y.; Matsui, M.; Miyagishima, S.-Y. The YlmG protein has a conserved function related to the distribution of nucleoids in chloroplasts and cyanobacteria. BMC Plant Biol. 2010, 10, 57. [CrossRef]

100. Zheng, X.; O'Shea, E.K. Cyanobacteria maintain constant protein concentration despite genome copy-number variation. Cell Rep. 2017, 19, 497-504. [CrossRef]

101. Burnat, M.; Schleiff, E.; Flores, E. Cell envelope components influencing filament length in the heterocyst-forming cyanobacterium Anabaena sp. strain PCC 7120. J. Bacteriol. 2014, 196, 4026-4035. [CrossRef] [PubMed]

102. Iyer, L.M.; Makarova, K.S.; Koonin, E.V.; Aravind, L. Comparative genomics of the FtsK-HerA superfamily of pumping ATPases: Implications for the origins of chromosome segregation, cell division and viral capsid packaging. Nucleic Acids Res. 2004, 32, 5260-5279. [CrossRef] [PubMed]

103. Mandakovic, D.; Trigo, C.; Andrade, D.; Riquelme, B.; Gómez-Lillo, G.; Soto-Liebe, K.; Díez, B.; Vásquez, M. CyDiv, a conserved and novel filamentous cyanobacterial cell division protein involved in septum localization. Front. Microbiol. 2016, 7, 1-11. [CrossRef] [PubMed]

104. Leganés, F.; Blanco-Rivero, A.; Fernández-Piñas, F.; Redondo, M.; Fernández-Valiente, E.; Fan, Q.; Lechno-Yossef, S.; Wolk, C.P. Wide variation in the cyanobacterial complement of presumptive penicillin-binding proteins. Arch. Microbiol. 2005, 184, 234-248. [CrossRef]

105. Berendt, S.; Lehner, J.; Zhang, Y.V.; Rasse, T.M.; Forchhammer, K.; Maldener, I. Cell wall amidase amic1 is required for cellular communication and heterocyst development in the cyanobacterium Anabaena PCC 7120 but not for filament integrity. J. Bacteriol. 2012, 194, 5218-5227. [CrossRef]

106. Rexroth, S.; Mullineaux, C.W.; Ellinger, D.; Sendtko, E.; Rögner, M.; Koenig, F. The plasma membrane of the cyanobacterium Gloeobacter violaceus contains segregated bioenergetic domains. Plant Cell 2011, 23, 2379LP-2390. [CrossRef]

107. Mitschke, J.; Georg, J.; Scholz, I.; Sharma, C.M.; Dienst, D.; Bantscheff, J.; Voß, B.; Steglich, C.; Wilde, A.; Vogel, J.; et al. An experimentally anchored map of transcriptional start sites in the model cyanobacterium Synechocystis sp. PCC6803. Proc. Natl. Acad. Sci. USA 2011, 108, 2124LP-2129LP. [CrossRef] [PubMed] 
108. Mitschke, J.; Vioque, A.; Haas, F.; Hess, W.R.; Muro-Pastor, A.M. Dynamics of transcriptional start site selection during nitrogen stress-induced cell differentiation in Anabaena sp. PCC7120. Proc. Natl. Acad. Sci. USA 2011, 108, 20130-20135. [CrossRef] [PubMed]

109. Flaherty, B.L.; Van Nieuwerburgh, F.; Head, S.R.; Golden, J.W. Directional RNA deep sequencing sheds new light on the transcriptional response of Anabaena sp. strain PCC 7120 to combined-nitrogen deprivation. BMC Genom. 2011, 12, 332. [CrossRef] [PubMed]

110. Stöckel, J.; Elvitigala, T.R.; Liberton, M.; Pakrasi, H.B. Carbon availability affects diurnally controlled processes and cell morphology of cyanothece 51142. PLoS ONE 2013, 8, 1-10. [CrossRef]

111. Khayatan, B.; Meeks, J.C.; Risser, D.D. Evidence that a modified type IV pilus-like system powers gliding motility and polysaccharide secretion in filamentous cyanobacteria. Mol. Microbiol. 2015, 98, 1021-1036. [CrossRef]

112. Marbouty, M.; Mazouni, K.; Saguez, C.; Cassier-Chauvat, C.; Chauvat, F. Characterization of the Synechocystis strain PCC 6803 penicillin-binding proteins and cytokinetic proteins FtsQ and FtsW and their network of interactions with ZipN. J. Bacteriol. 2009, 191, 5123-5133. [CrossRef]

113. Bornikoel, J.; Staiger, J.; Madlung, J.; Forchhammer, K.; Maldener, I. LytM factor Alr3353 affects filament morphology and cell-cell communication in the multicellular cyanobacterium Anabaena sp. PCC 7120. Mol. Microbiol. 2018, 108, 187-203. [CrossRef]

114. Flores, E.; Pernil, R.; Muro-Pastor, A.M.; Mariscal, V.; Maldener, I.; Lechno-Yossef, S.; Fan, Q.; Wolk, C.P.; Herrero, A. Septum-localized protein required for filament integrity and diazotrophy in the heterocyst-forming cyanobacterium Anabaena sp. strain PCC 7120. J. Bacteriol. 2007, 189, 3884-3890. [CrossRef]

115. Merino-Puerto, V.; Mariscal, V.; Mullineaux, C.W.; Herrero, A.; Flores, E. Fra proteins influencing filament integrity, diazotrophy and localization of septal protein SepJ in the heterocyst-forming cyanobacterium Anabaena sp. Mol. Microbiol. 2010, 75, 1159-1170. [CrossRef]

116. Sakr, S.; Thyssen, M.; Denis, M.; Zhang, C.C. Relationship among several key cell cycle events in the developmental cyanobacterium Anabaena sp. strain PCC 7120. J. Bacteriol. 2006, 188, 5958-5965. [CrossRef]

117. Koksharova, O.A.; Klint, J.; Rasmussen, U. Comparative proteomics of cell division mutants and wild-type of Synechococcus sp. strain PCC 7942. Microbiology 2007, 153, 2505-2517. [CrossRef] [PubMed]

118. Hernández-Muñiz, W.; Stevens, S.E. Characterization of the motile hormogonia of Mastigocladus laminosus. J. Bacteriol. 1987, 169, 218LP-223LP. [CrossRef]

119. González, A.; Fillat, M.F.; Bes, M.-T.; Peleato, M.-L.; Sevilla, E. The challenge of Iron stress in Cyanobacteria. In Cyanobacteria; IntechOpen: London, UK, 2018.

120. González, A.; Bes, M.T.; Valladares, A.; Peleato, M.L.; Fillat, M.F. FurA is the master regulator of iron homeostasis and modulates the expression of tetrapyrrole biosynthesis genes in A nabaena sp. PCC 7120. Environ. Microbiol. 2012, 14, 3175-3187. [CrossRef] [PubMed]

121. González, A.; Bes, M.T.; Barja, F.; Peleato, M.L.; Fillat, M.F. Overexpression of FurA in Anabaena sp. PCC 7120 reveals new targets for this regulator involved in photosynthesis, iron uptake and cellular morphology. Plant Cell Physiol. 2010, 51, 1900-1914. [CrossRef] [PubMed]

122. Hsu, Y.-P.; Rittichier, J.; Kuru, E.; Yablonowski, J.; Pasciak, E.; Tekkam, S.; Hall, E.; Murphy, B.; Lee, T.K.; Garner, E.C.; et al. Full color palette of fluorescent d-amino acids for in situ labeling of bacterial cell walls. Chem. Sci. 2017, 8, 6313-6321. [CrossRef] [PubMed]

123. Zhang, J.Y.; Lin, G.M.; Xing, W.Y.; Zhang, C.C. Diversity of growth patterns probed in live cyanobacterial cells using a fluorescent analog of a peptidoglycan precursor. Front. Microbiol. 2018, 9, 1-10. [CrossRef] [PubMed]

124. Laddomada, F.; Miyachiro, M.M.; Dessen, A. Structural insights into protein-protein interactions involved in bacterial cell wall biogenesis. Antibiotics 2016, 5, 14. [CrossRef]

125. Lázaro, S.; Fernández-Piñas, F.; Fernández-Valiente, E.; Blanco-Rivero, A.; Leganés, F. PbpB, a gene coding for a putative penicillin-binding protein, is required for aerobic nitrogen fixation in the cyanobacterium Anabaena sp. strain PCC7120. J. Bacteriol. 2001, 183, 628-636. [CrossRef]

126. Zhu, J.; Jäger, K.; Black, T.; Zarka, K.; Koksharova, O.; Wolk, C.P. HcwA, an autolysin, is required for heterocyst maturation in Anabaena sp. strain PCC 7120. J. Bacteriol. 2001, 183, 6841LP-6851LP. [CrossRef]

127. Fenton, A.K.; Gerdes, K. Direct interaction of FtsZ and MreB is required for septum synthesis and cell division in Escherichia coli. EMBO J. 2013, 32, 1953-1965. [CrossRef] 
128. Osawa, M.; Anderson, D.E.; Erickson, H.P. Reconstitution of contractile FtsZ rings in liposomes. Science 2008, 320, 792-794. [CrossRef] [PubMed]

129. Osawa, M.; Anderson, D.E.; Erickson, H.P. Curved FtsZ protofilaments generate bending forces on liposome membranes. EMBO J. 2009, 28, 3476-3484. [CrossRef] [PubMed]

130. Lutkenhaus, J.; Du, S.E. coli Cell Cycle Machinery. In Prokaryotic Cytoskeletons: Filamentous Protein Polymers Active in the Cytoplasm of Bacterial and Archaeal Cells; Löwe, J., Amos, L.A., Eds.; Springer: Berlin/Heidelberg, Germany, 2017; pp. 27-65.

131. Den Blaauwen, T.; Hamoen, L.W.; Levin, P.A. The divisome at 25: The road ahead. Curr. Opin. Microbiol. 2017, 36, 85-94. [CrossRef] [PubMed]

132. Camargo, S.; Picossi, S.; Corrales-Guerrero, L.; Valladares, A.; Arévalo, S.; Herrero, A. ZipN is an essential FtsZ membrane tether and contributes to the septal localization of SepJ in the filamentous cyanobacterium Anabaena. Sci. Rep. 2019, 9, 1-15. [CrossRef] [PubMed]

133. Valladares, A.; Velázquez-Suárez, C.; Herrero, A. Interactions of PatA with the divisome during heterocyst differentiation in Anabaena. mSphere 2020, 5, e00188-20. [CrossRef] [PubMed]

134. Gorelova, O.A.; Baulina, O.I.; Rasmussen, U.; Koksharova, O.A. The pleiotropic effects of ftn2 and ftn6 mutations in cyanobacterium Synechococcus sp. PCC 7942: An ultrastructural study. Protoplasma 2013, 250, 931-942. [CrossRef]

135. Chen, C.; MacCready, J.S.; Ducat, D.C.; Osteryoung, K.W. The molecular machinery of chloroplast division. Plant Physiol. 2018, 176, 138-151. [CrossRef]

136. Yoshida, Y.; Mogi, Y.; TerBush, A.D.; Osteryoung, K.W. Chloroplast FtsZ assembles into a contractible ring via tubulin-like heteropolymerization. Nat. Plants 2016, 2, 16095. [CrossRef]

137. Miyagishima, S.; Nakamura, M.; Uzuka, A.; Era, A. FtsZ-less prokaryotic cell division as well as FtsZ- and dynamin-less chloroplast and non-photosynthetic plastid division. Front. Plant Sci. 2014, 5, 1-13. [CrossRef]

138. Zhang, C.-C.C.; Hugenin, S.; Friry, A.; Huguenin, S.; Friry, A. Analysis of genes encoding the cell division protein FtsZ and a glutathione synthetase homologue in the cyanobacterium Anabaena sp. PCC 7120. Res. Microbiol. 1995, 146, 445-455. [CrossRef]

139. Wang, N.; Bian, L.; Ma, X.; Meng, Y.; Chen, C.S.; Ur Rahman, M.; Zhang, T.; Li, Z.; Wang, P.; Chen, Y. Assembly properties of the bacterial tubulin homolog FtsZ from the cyanobacterium Synechocystis sp. PCC 6803. J. Biol. Chem. 2019, 294, 16309-16319. [CrossRef]

140. Corrales-Guerrero, L.; Camargo, S.; Valladares, A.; Picossi, S.; Luque, I.; Ochoa De Alda, J.A.G.; Herrero, A. FtsZ of filamentous, heterocyst-forming cyanobacteria has a conserved N-terminal peptide required for normal FtsZ polymerization and cell division. Front. Microbiol. 2018, 9, 1-20. [CrossRef] [PubMed]

141. Duman, R.; Ishikawa, S.; Celik, I.; Strahl, H.; Ogasawara, N.; Troc, P.; Löwe, J.; Hamoen, L.W. Structural and genetic analyses reveal the protein $\mathrm{SepF}$ as a new membrane anchor for the $\mathrm{Z}$ ring. Proc. Natl. Acad. Sci. USA 2013, 110, E4601-E4610. [CrossRef] [PubMed]

142. Erickson, H.P.; Anderson, D.E.; Osawa, M. FtsZ in bacterial cytokinesis: Cytoskeleton and force generator all in one. Microbiol. Mol. Biol. Rev. 2010, 74, 504-528. [CrossRef] [PubMed]

143. Liu, R.; Liu, Y.; Liu, S.; Wang, Y.; Li, K.; Li, N.; Xu, D.; Zeng, Q. Three-dimensional superresolution imaging of the FtsZ ring during cell division of the cyanobacterium prochlorococcus. MBio 2017, 8, 1-11. [CrossRef] [PubMed]

144. Abed, R.M.; Garcia-Pichel, F.; Hernández-Mariné, M. Polyphasic characterization of benthic, moderately halophilic, moderately thermophilic cyanobacteria with very thin trichomes and the proposal of Halomicronema excentricum gen. nov., sp. nov. Arch. Microbiol. 2002, 177, 361-370. [CrossRef]

145. Sarcina, M.; Mullineaux, C.W. Effects of tubulin assembly inhibitors on cell division in prokaryotes in vivo. FEMS Microbiol. Lett. 2000, 191, 25-29. [CrossRef]

146. Billi, D. Loss of topological relationships in a Pleurocapsalean cyanobacterium (Chroococcidiopsis sp.) with partially inactivatedftsZ. Ann. Microbiol. 2009, 59, 235. [CrossRef]

147. Mori, T.; Johnson, C.H. Independence of circadian timing from cell division in cyanobacteria. J. Bacteriol. 2001, 183, 2439-2444. [CrossRef]

148. Yoshida, T.; Maki, M.; Okamoto, H.; Hiroishi, S. Coordination of DNA replication and cell division in Cyanobacteria Microcystis aeruginosa. FEMS Microbiol. Lett. 2005, 251, 149-154. [CrossRef] 
149. Esteves-Ferreira, A.A.; Inaba, M.; Obata, T.; Fort, A.; Fleming, G.T.A.; Araújo, W.L.; Fernie, A.R.; Sulpice, R. A novel mechanism, linked to cell density, largely controls cell division in synechocystis. Plant Physiol. 2017, 174, 2166-2182. [CrossRef] [PubMed]

150. Dong, G.; Yang, Q.; Wang, Q.; Kim, Y.-I.; Wood, T.L.; Osteryoung, K.W.; van Oudenaarden, A.; Golden, S.S. Elevated ATPase activity of KaiC applies a circadian checkpoint on cell division in Synechococcus elongatus. Cell 2010, 140, 529-539. [CrossRef] [PubMed]

151. Sandh, G.; El-Shehawy, R.; Díez, B.; Bergman, B. Temporal separation of cell division and diazotrophy in the marine diazotrophic cyanobacterium Trichodesmium erythraeum IMS101. FEMS Microbiol. Lett. 2009, 295, 281-288. [CrossRef] [PubMed]

152. Sakr, S.; Jeanjean, R.; Zhang, C.-C.; Arcondeguy, T. Inhibition of cell division suppresses heterocyst development in Anabaena sp. strain PCC 7120. J. Bacteriol. 2006, 188, 1396-1404. [CrossRef]

153. Klint, J.; Rasmussen, U.; Bergman, B. FtsZ may have dual roles in the filamentous cyanobacterium Nostoc/Anabaena sp. strain PCC 7120. J. Plant Physiol. 2007, 164, 11-18. [CrossRef]

154. Wang, Y.; $\mathrm{Xu}, \mathrm{X}$. Regulation by hetC of genes required for heterocyst differentiation and cell division in Anabaena sp. strain PCC 7120. J. Bacteriol. 2005, 187, 8489-8493. [CrossRef]

155. Kuhn, I.; Peng, L.; Bedu, S. Developmental regulation of the cell division protein FtsZ in Anabaena sp. strain PCC 7120, a cyanobacterium capable of terminal differentiation. J. Bacteriol. 2000, 182, 4640-4643. [CrossRef]

156. Golubić, S.; Hernández-Mariné, M.; Hoffmann, L. Developmental aspects of branching in filamentous Cyanophyta/cyanobacteria. Algol. Stud. Für Hydrobiol. Suppl. Vol. 1996, 83, 303-329. [CrossRef]

157. Lopes Pinto, F.; Erasmie, S.; Blikstad, C.; Lindblad, P.; Oliveira, P. FtsZ degradation in the cyanobacterium Anabaena sp. strain PCC 7120. J. Plant Physiol. 2011, 168, 1934-1942. [CrossRef]

158. Goclaw-Binder, H.; Sendersky, E.; Shimoni, E.; Kiss, V.; Reich, Z.; Perelman, A.; Schwarz, R. Nutrient-associated elongation and asymmetric division of the cyanobacterium Synechococcus PCC 7942. Environ. Microbiol. 2012, 14, 680-690. [CrossRef]

159. Yamauchi, Y.; Kaniya, Y.; Kaneko, Y.; Hihara, Y. Physiological roles of the cyAbrB transcriptional regulator pair Sll0822 and Sll0359 in synechocystis sp. strain PCC 6803. J. Bacteriol. 2011, 193, 3702-3709. [CrossRef] [PubMed]

160. He, D.; Xu, X. CalA, a cyAbrB protein, binds to the upstream region of $\mathrm{fts} Z$ and is down-regulated in heterocysts in Anabaena sp. PCC 7120. Arch. Microbiol. 2010, 192, 461-469. [CrossRef] [PubMed]

161. Jain, I.H.; Vijayan, V.; O'Shea, E.K. Spatial ordering of chromosomes enhances the fidelity of chromosome partitioning in cyanobacteria. Proc. Natl. Acad. Sci. USA 2012, 109, 13638-13643. [CrossRef] [PubMed]

162. Chen, A.H.; Afonso, B.; Silver, P.A.; Savage, D.F. Spatial and temporal organization of chromosome duplication and segregation in the cyanobacterium synechococcus elongatus PCC 7942. PLoS ONE 2012, 7,1-10. [CrossRef] [PubMed]

163. Szwedziak, P.; Wang, Q.; Freund, S.M.; Löwe, J. FtsA forms actin-like protofilaments. EMBO J. 2012, 31, 2249-2260. [CrossRef]

164. Loose, M.; Mitchison, T.J. The bacterial cell division proteins ftsA and ftsZ self-organize into dynamic cytoskeletal patterns. Nat. Cell Biol. 2014, 16, 38-46. [CrossRef]

165. Du, S.; Lutkenhaus, J. Assembly and activation of the Escherichia coli divisome. Mol. Microbiol. 2017, 105, 177-187. [CrossRef]

166. Pichoff, S.; Lutkenhaus, J. Unique and overlapping roles for ZipA and FtsA in septal ring assembly in Escherichia coli. EMBO J. 2002, 21, 685-693. [CrossRef]

167. Jensen, S.O.; Thompson, L.S.; Harry, E.J. Cell division in Bacillus subtilis: FtsZ and FtsA association is Z-ring independent, and FtsA is required for efficient midcell Z-ring assembly. J. Bacteriol. 2005, 187, 6536LP-6544LP. [CrossRef]

168. Hamoen, L.W.; Meile, J.-C.; De Jong, W.; Noirot, P.; Errington, J. SepF, a novel FtsZ-interacting protein required for a late step in cell division. Mol. Microbiol. 2006, 59, 989-999. [CrossRef]

169. Vitha, S.; Froehlich, J.E.; Koksharova, O.; Pyke, K.A.; van Erp, H.; Osteryoung, K.W. ARC6 is a J-domain plastid division protein and an evolutionary descendant of the cyanobacterial cell division protein Ftn2. Plant Cell 2003, 15, 1918-1933. [CrossRef] [PubMed]

170. Singh, J.K.; Makde, R.D.; Kumar, V.; Panda, D. SepF increases the assembly and bundling of FtsZ polymers and stabilizes FtsZ protofilaments by binding along its length. J. Biol. Chem. 2008, 283, 31116-31124. [CrossRef] [PubMed] 
171. MacCready, J.S.; Hakim, P.; Young, E.J.; Hu, L.; Liu, J.; Osteryoung, K.W.; Vecchiarelli, A.G.; Ducat, D.C. Protein gradients on the nucleoid position the carbon-fixing organelles of cyanobacteria. elife 2018, 7, 1-33. [CrossRef] [PubMed]

172. Springstein, B.L.; Arévalo, S.; Helbig, A.O.; Herrero, A.; Stucken, K.; Flores, E.; Dagan, T. A novel septal protein of multicellular heterocystous cyanobacteria is associated with the divisome. Mol. Microbiol. 2020, 113, 1140-1154. [CrossRef] [PubMed]

173. Marbouty, M.; Saguez, C.; Chauvat, F. The cyanobacterial cell division factor Ftn6 contains an N-terminal DnaD-like domain. BMC Struct. Biol. 2009, 9, 1-7. [CrossRef]

174. Rudolf, M.; Tetik, N.; Ramos-León, F.; Flinner, N.; Ngo, G.; Stevanovic, M.; Burnat, M.; Pernil, R.; Flores, E.; Schleiff, E. The peptidoglycan-binding protein $\mathrm{SjcF} 1$ influences septal junction function and channel formation in the filamentous cyanobacterium Anabaena. MBio 2015, 6, e00376-15. [CrossRef]

175. Zheng, Z.; Omairi-Nasser, A.; Li, X.; Dong, C.; Lin, Y.; Haselkorn, R.; Zhao, J. An amidase is required for proper intercellular communication in the filamentous cyanobacterium Anabaena sp. PCC 7120. Proc. Natl. Acad. Sci. USA 2017, 114, E1405-E1412. [CrossRef]

176. D’Ulisse, V.; Fagioli, M.; Ghelardini, P.; Paolozzi, L. Three functional subdomains of the Escherichia coli FtsQ protein are involved in its interaction with the other division proteins. Microbiology 2007, 153, 124-138. [CrossRef]

177. Mariscal, V.; Nürnberg, D.J.; Herrero, A.; Mullineaux, C.W.; Flores, E. Overexpression of SepJ alters septal morphology and heterocyst pattern regulated by diffusible signals in Anabaena. Mol. Microbiol. 2016, 101, 968-981. [CrossRef]

178. Karimova, G.; Dautin, N.; Ladant, D. Interaction network among Escherichia coli membrane proteins involved in cell division as revealed by bacterial two-hybrid analysis. J. Bacteriol. 2005, 187, 2233LP-2243LP. [CrossRef]

179. Cho, H. The role of cytoskeletal elements in shaping bacterial cells. J. Microbiol. Biotechnol. 2015, 25, 307-316. [CrossRef] [PubMed]

180. Szwedziak, P.; Ghosal, D. FtsZ-ring architecture and its control by MinCD. In Prokaryotic Cytoskeletons: Filamentous Protein Polymers Active in the Cytoplasm of Bacterial and Archaeal Cells; Löwe, J., Amos, L.A., Eds.; Springer: Berlin/Heidelberg, Germany, 2017; pp. 213-244.

181. Mukherjee, A.; Cao, C.; Lutkenhaus, J. Inhibition of FtsZ polymerization by SulA, an inhibitor of septation in Escherichia coli. Proc. Natl. Acad. Sci. USA 1998, 95, 2885LP-2890LP. [CrossRef] [PubMed]

182. Bi, E.; Lutkenhaus, J. Cell division inhibitors SulA and MinCD prevent formation of the FtsZ ring. J. Bacteriol. 1993, 175, 1118LP-1125LP. [CrossRef] [PubMed]

183. Raynaud, C.; Cassier-Chauvat, C.; Perennes, C.; Bergounioux, C. An Arabidopsis homolog of the bacterial cell division inhibitor SulA is involved in plastid division. Plant Cell 2004, 16, 1801-1811. [CrossRef] [PubMed]

184. Mukherjee, A.; Lutkenhaus, J. Dynamic assembly of FtsZ regulated by GTP hydrolysis. EMBO J. 1998, 17, 462-469.e6. [CrossRef]

185. Murray, S.M.; Howard, M. Center finding in E. coli and the role of mathematical modeling: Past, present and future. J. Mol. Biol. 2019, 431, 928-938. [CrossRef]

186. Jordan, A.; Chandler, J.; MacCready, J.S.; Huang, J.; Osteryoung, K.W.; Ducat, D.C. Engineering cyanobacterial cell morphology for enhanced recovery and processing of biomass. Appl. Environ. Microbiol. 2017, 83, 1-13. [CrossRef]

187. Liao, Y.; Rust, M.J. The min oscillator defines sites of asymmetric cell division in cyanobacteria during stress recovery. Cell Syst. 2018, 7, 471-481.e6. [CrossRef]

188. Fuchs, E.; Weber, K. Intermediate Filaments: Structure, dynamics, function and disease. Annu. Rev. Biochem. 1994, 63, 345-382. [CrossRef]

189. Herrmann, H.; Aebi, U. Intermediate filaments: Structure and assembly. Cold Spring Harb. Perspect. Biol. 2016, 8, a018242. [CrossRef]

190. Sundararajan, K.; Goley, E.D. Cytoskeletal proteins in caulobacter crescentus: Spatial orchestrators of cell cycle progression, development, and cell shape. Subcell. Biochem. 2017, 84, 103-137. [PubMed]

191. Van Teeseling, M.C.F.; de Pedro, M.A.; Cava, F. Determinants of bacterial morphology: From fundamentals to possibilities for antimicrobial targeting. Front. Microbiol. 2017, 8, 1-18. [CrossRef] [PubMed]

192. Hurme, R.; Namork, E.; Nurmiaho-Lassila, E.L.; Rhen, M. Intermediate filament-like network formed in vitro by a bacterial coiled coil protein. J. Biol. Chem. 1994, 269, 10675-10682. 
193. Kelemen, G.H. Intermediate filaments supporting cell shape and growth in bacteria. In Prokaryotic Cytoskeletons: Filamentous Protein Polymers Active in the Cytoplasm of Bacterial and Archaeal Cells; Löwe, J., Amos, L.A., Eds.; Springer: Berlin/Heidelberg, Germany, 2017; pp. 161-211.

194. Erickson, H.P. Evolution of the cytoskeleton. Bioessays 2007, 29, 668-677. [CrossRef]

195. Wickstead, B.; Gull, K. The evolution of the cytoskeleton. J. Cell Biol. 2011, 194, 513-525. [CrossRef]

196. Fiuza, M.; Letek, M.; Leiba, J.; Villadangos, A.F.; Vaquera, J.; Zanella-Cléon, I.; Mateos, L.M.; Molle, V.; Gil, J.A. Phosphorylation of a novel cytoskeletal protein (RsmP) regulates rod-shaped morphology in Corynebacterium glutamicum. J. Biol. Chem. 2010, 285, 29387-29397. [CrossRef]

197. Bagchi, S.; Tomenius, H.; Belova, L.M.; Ausmees, N. Intermediate filament-like proteins in bacteria and a cytoskeletal function in Streptomyces. Mol. Microbiol. 2008, 70, 1037-1050. [PubMed]

198. Holmes, N.A.; Walshaw, J.; Leggett, R.M.; Thibessard, A.; Dalton, K.A.; Gillespie, M.D.; Hemmings, A.M.; Gust, B.; Kelemen, G.H. Coiled-coil protein Scy is a key component of a multiprotein assembly controlling polarized growth in Streptomyces. Proc. Natl. Acad. Sci. USA 2013, 110, E397-E406. [CrossRef]

199. Fröjd, M.J.; Flärdh, K. Apical assemblies of intermediate filament-like protein FilP are highly dynamic and affect polar growth determinant DivIVA in Streptomyces venezuelae. Mol. Microbiol. 2019, 112, 47-61. [CrossRef]

200. England, P.; Bourhy, P.; Picardeau, M.; Saint Girons, I.; Mazouni, K.; Pehau-Arnaudet, G. The scc spirochetal coiled-coil protein forms helix-like filaments and binds to nucleic acids generating nucleoprotein structures. J. Bacteriol. 2005, 188, 469-476.

201. Yang, R.; Bartle, S.; Otto, R.; Rogers, M.; Plamann, L.; Hartzell, P.L.; Stassinopoulos, A. Ag1Z is a filament-forming coiled-coil protein required for adventurous gliding motility of Myxococcus xanthus. J. Bacteriol. 2004, 186, 6168-6178. [CrossRef] [PubMed]

202. Specht, M.; Schätzle, S.; Graumann, P.L.; Waidner, B. Helicobacter pylori possesses four coiled-coil-rich proteins that form extended filamentous structures and control cell shape and motility. J. Bacteriol. 2011, 193, 4523-4530. [CrossRef] [PubMed]

203. Köster, S.; Weitz, D.A.; Goldman, R.D.; Aebi, U.; Herrmann, H. Intermediate filament mechanics in vitro and in the cell: From coiled coils to filaments, fibers and networks. Curr. Opin. Cell Biol. 2015, 32, 82-91. [CrossRef] [PubMed]

204. Springstein, B.L.; Woehle, C.; Weissenbach, J.; Helbig, A.O.; Dagan, T.; Stucken, K. Identification and characterization of novel filament-forming proteins in cyanobacteria. Sci. Rep. 2020, 10, 1894. [CrossRef]

205. Scanlan, D.J.; Ostrowski, M.; Mazard, S.; Dufresne, A.; Garczarek, L.; Hess, W.R.; Post, A.F.; Hagemann, M.; Paulsen, I.; Partensky, F. Ecological genomics of marine picocyanobacteria. Microbiol. Mol. Biol. Rev. 2009, 73, 249-299. [CrossRef]

206. Cho, Y.W.; Gonzales, A.; Harwood, T.V.; Huynh, J.; Hwang, Y.; Park, J.S.; Trieu, A.Q.; Italia, P.; Pallipuram, V.K.; Risser, D.D. Dynamic localization of $\mathrm{HmpF}$ regulates type IV pilus activity and directional motility in the filamentous cyanobacterium Nostoc punctiforme. Mol. Microbiol. 2017, 106, 252-265. [CrossRef]

207. Bhaya, D.; Takahashi, A.; Shahi, P.; Arthur, R. Novel motility mutants of synechocystis strain PCC 6803 generated by in vitro transposon mutagenesis. J. Bacteriol. 2001, 183, 1-5. [CrossRef]

208. Herrmann, H.; Aebi, U. Intermediate filaments: Molecular structure, assembly mechanism, and integration into functionally distinct intracellular scaffolds. Annu. Rev. Biochem. 2004, 73, 749-789. [CrossRef]

209. Šmarda, J.; Šmajs, D.; Komrska, J.; Krzyžánek, V. S-layers on cell walls of cyanobacteria. Micron 2002, 33, 257-277. [CrossRef]

210. Cohen, S.E.; McKnight, B.M.; Golden, S.S. Roles for ClpXP in regulating the circadian clock in Synechococcus elongatus. Proc. Natl. Acad. Sci. USA 2018, 115, E7805-E7813. [CrossRef]

211. Springstein, B.L.; Nürnberg, D.J.; Woehle, C.; Weissenbach, J.; Theune, M.L.; Helbig, A.O.; Maldener, I.; Dagan, T.; Stucken, K. Two novel heteropolymer-forming proteins maintain the multicellular shape of the cyanobacterium Anabaena sp. PCC 7120. FEBS J. 2020. [CrossRef] [PubMed]

212. Lupas, A.; Van Dyke, M.; Stock, J. Predicting coiled coils from protein sequences. Science 1991, 252, $1162-1164$. [CrossRef] [PubMed]

213. Bailey-Watts, A.E.; Bindloss, M.E. Freshwater primary production by a blue-green alga of bacterial size. Nature 1968, 220, 1344-1345. [CrossRef]

214. Bisalputra, T.; Oakley, B.R.; Walker, D.C.; Shields, C.M. Microtubular complexes in blue-green algae. Protoplasma 1975, 86, 19-28. [CrossRef] 
215. Jensen, T.E.; Ayala, R.P. The fine structure of striated microtubules and sleeve bodies in several species of Anabaena. J. Ultrasruct. Res. 1976, 57, 185-193. [CrossRef]

216. Bermudes, D.; Hinkle, G.; Margulis, L. Do prokaryotes contain microtubules? Microbiol. Rev. 1994, 58, 387-400. [CrossRef]

217. Rast, A.; Schaffer, M.; Albert, S.; Wan, W.; Pfeffer, S.; Beck, F.; Plitzko, J.M.; Nickelsen, J.; Engel, B.D. Biogenic regions of cyanobacterial thylakoids form contact sites with the plasma membrane. Nat. Plants 2019, 5, 436-446. [CrossRef]

218. Jensen, T.E.; Ayala, R.P. Microtubule-like inclusions in isolates of the blue-green bacteria Anabaena and Nostoc. Cytologia 1980, 45, 315-326. [CrossRef]

219. Basler, M.; Pilhofer, M.; Henderson, G.P.; Jensen, G.J.; Mekalanos, J.J. Type VI secretion requires a dynamic contractile phage tail-like structure. Nature 2012, 483, 182-186. [CrossRef]

220. Porta, D.; Rippka, R.; Hernández-Mariné, M. Unusual ultrastructural features in three strains of Cyanothece (cyanobacteria). Arch. Microbiol. 2000, 173, 154-163. [CrossRef]

221. Medeiros, J.M.; Böck, D.; Weiss, G.L.; Kooger, R.; Wepf, R.A.; Pilhofer, M. Robust workflow and instrumentation for cryo-focused ion beam milling of samples for electron cryotomography. Ultramicroscopy 2018, 190, 1-11. [CrossRef] [PubMed]

Publisher's Note: MDPI stays neutral with regard to jurisdictional claims in published maps and institutional affiliations.

(C) 2020 by the authors. Licensee MDPI, Basel, Switzerland. This article is an open access article distributed under the terms and conditions of the Creative Commons Attribution (CC BY) license (http://creativecommons.org/licenses/by/4.0/). 